الممارست البيئية الخلائة للمرأة الرفية والعولل المرتجلة بها بقربة نواج محاثلة الغربية

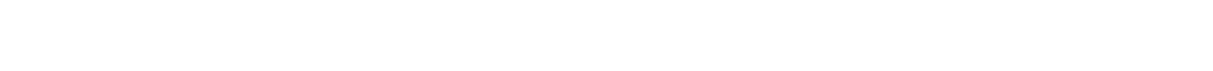

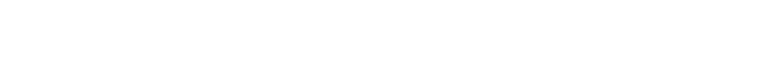

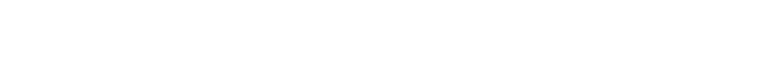

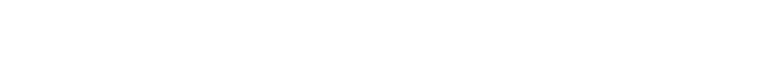

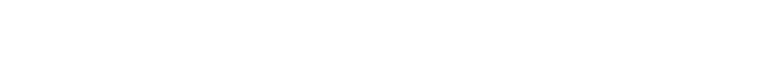

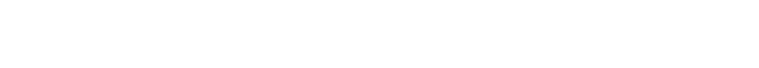

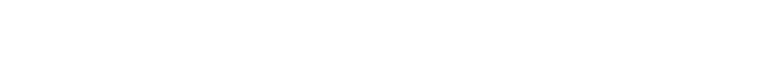

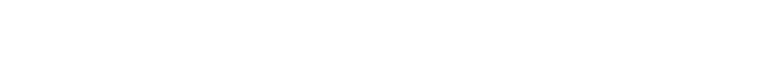

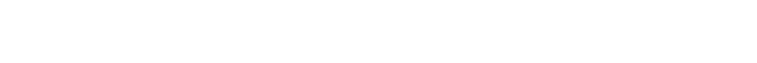

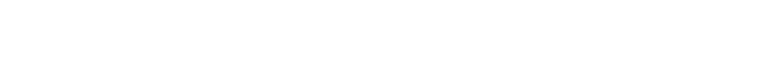

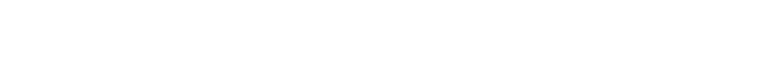

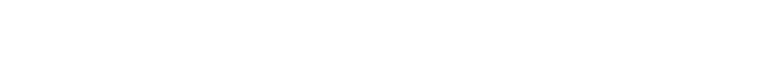

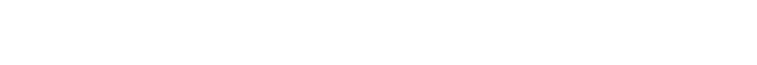
اللأسرة، وسسنوى المعيشة.

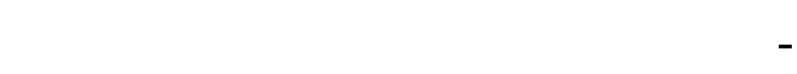

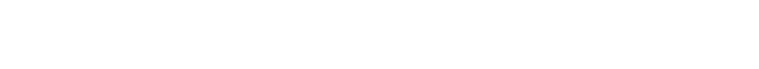

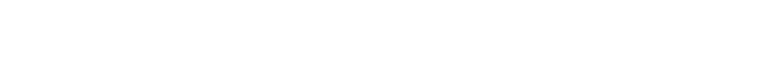

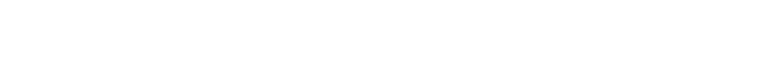

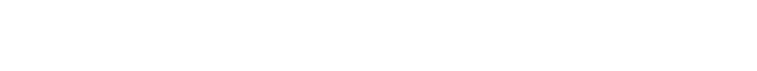

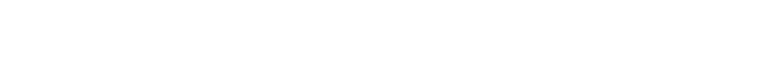

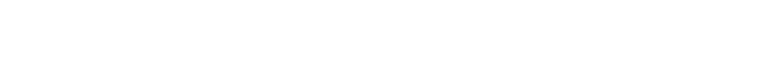

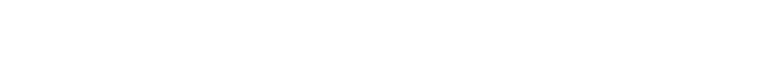

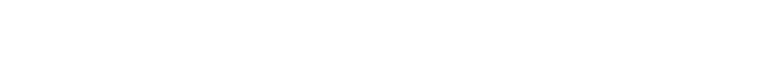

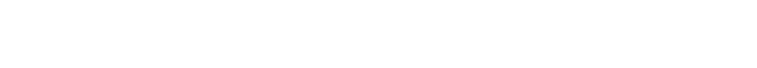

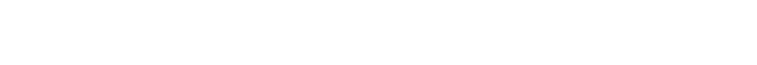

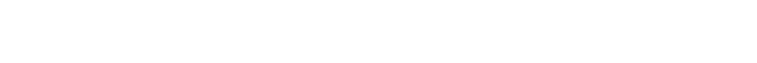
المغنيرك في فسير التبلين في المتغير التلع.
الملخص الهرص

بهف هذا البهث إلي العرف عل مستوى طلبق الرفيلت

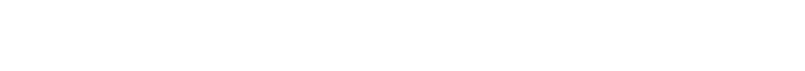

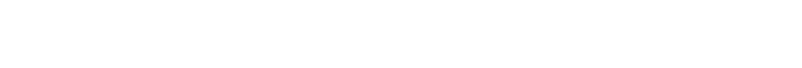

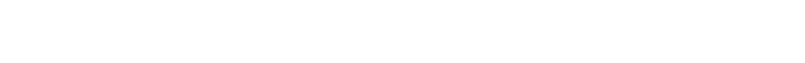
الممارسلت البيئية الخلائة للرفيلت لل بُمبد من الأبعاد الأربعة

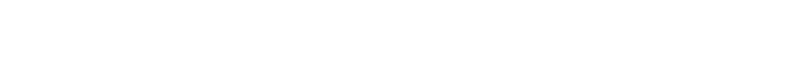

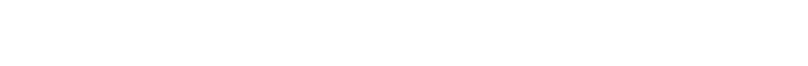

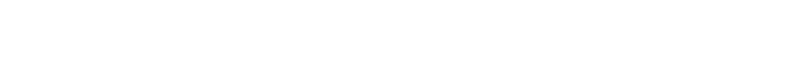

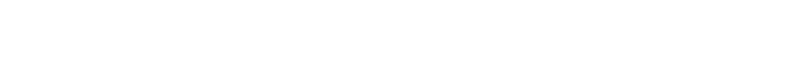
البيئية الخلائة لل بُدمن الأبعاد لأربهة المدروسة.

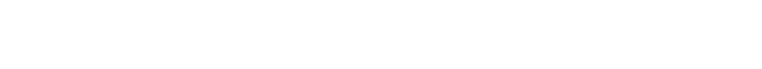

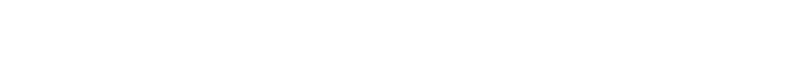

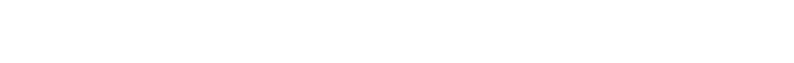

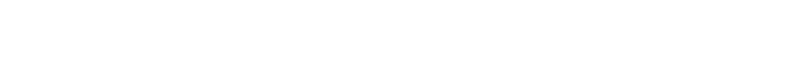

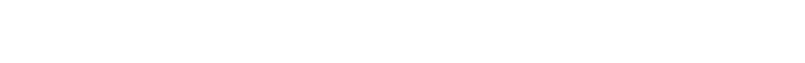

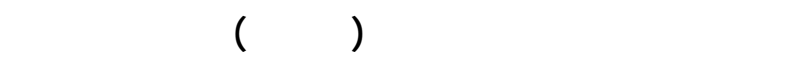
المتعد، ولانحدار الجزئ المعياري في تحلالل البيلنات. وكلت أهم النتائج التي توطل إلبها البهثما لئي:

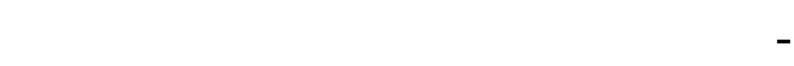

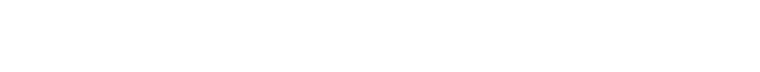

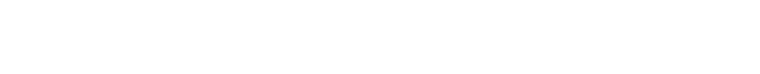

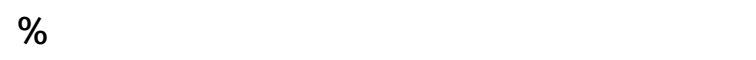

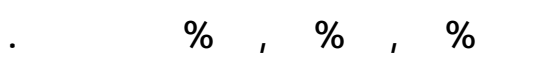

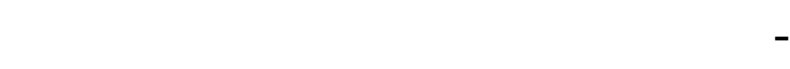

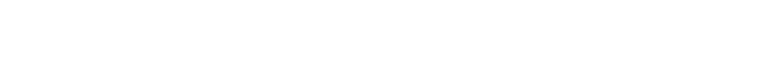

النستاذمساعد ورئيس قسم تنمية الأسرة الريفية-كلية الاقتصاد المنزلي

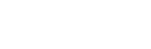
r بأستاذ الإششاد الزراعي المساءد -كلية الزراعة بالقاهرة -جامعة الأزهر

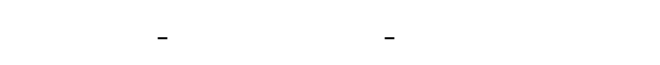

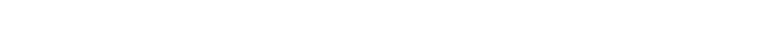




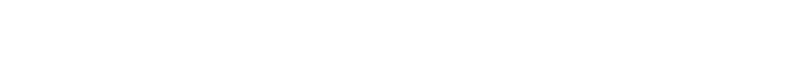

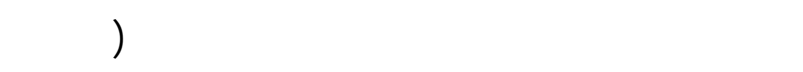

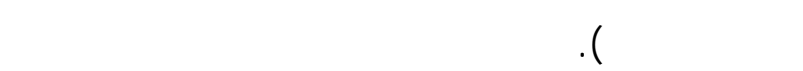
المخصبت الزراعية والمبيدات الهشرية أدى إل مي تلا ـوث التربة الزراعية.

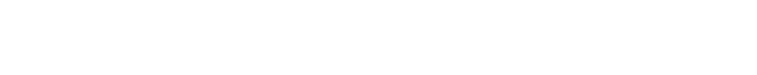

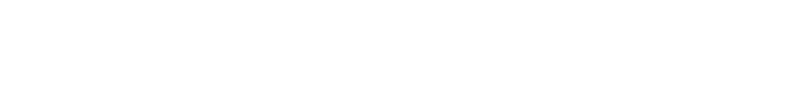
نصف عدد النساء المصريت (قرالبة 07\%) ممثل ـة بـ ذذلك

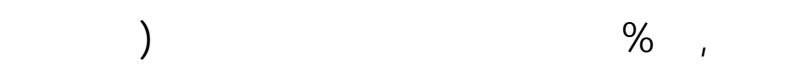

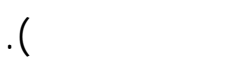
ولاثك أن المرأة الريفية لها دور كبي -ر وم -ؤثر ف مي

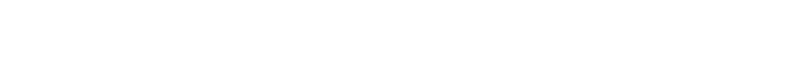

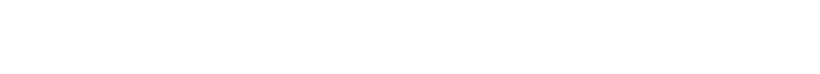
المرأة في المجتمع وتحد من مشاركتها ولسنهامها في مكلفحة

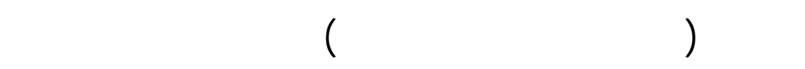

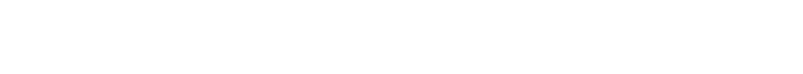

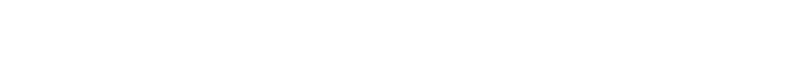
التعلل مع الموارد البيئية كالاستخدلم للسيئ للميه ولستعمل

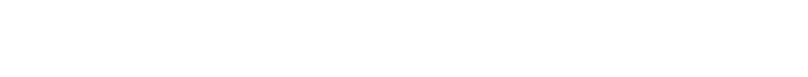

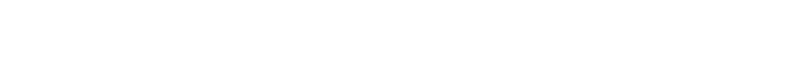

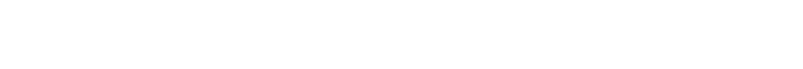

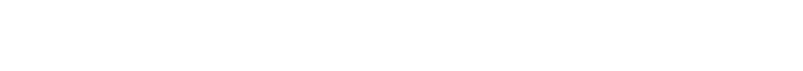

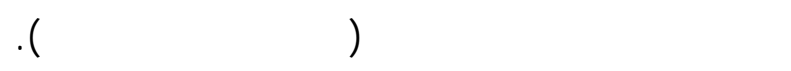

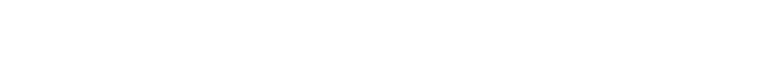
البيئية الخطئة للمرأة الريفية بإحدى قرى محلظة الغمية الغربي الفية حيث أن التعايث الواعي للمرأة الريفية وإدرلكها الحقيق مي المئي

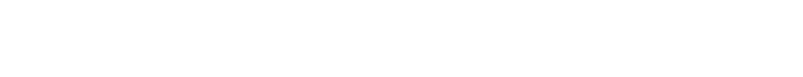
أهم الأسس التي تمكنها من للسلوك السليم تجه بيئتها، وعليه فإن الحماية الصحيحة للبيئة الريفية من التلوث لن يتأقت إلا بنشر الوعي البيئي السليم بين أفرادها.

\section{المقم - ـة}

أصبحت قضية البيئة وحمايتها والمحلفة عليه Lام ـن

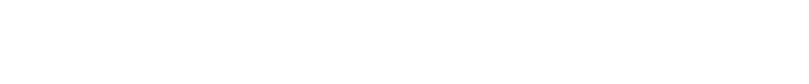

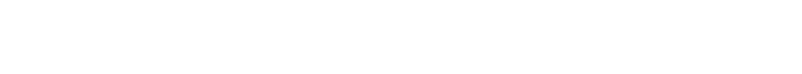

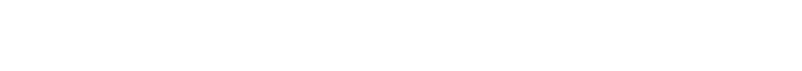

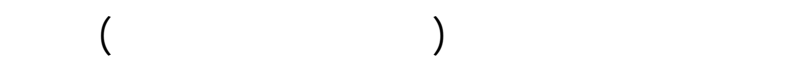

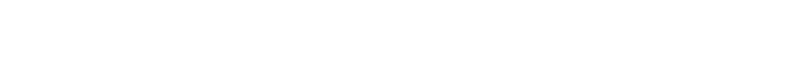

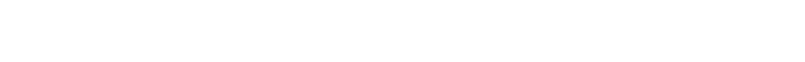

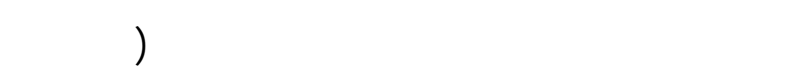

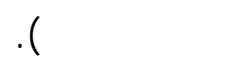

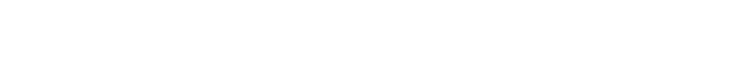

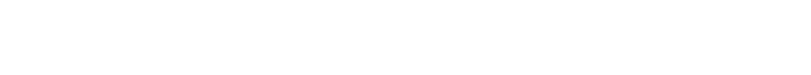
التلوث البيئي بيلثكاله المختلفة بصفة علمة وبالأخص ف في

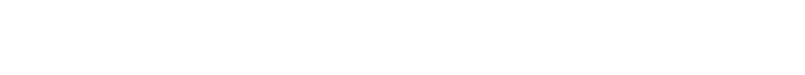

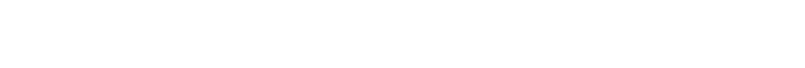

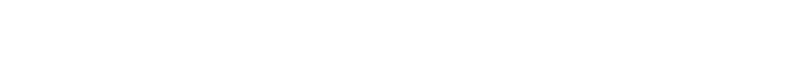

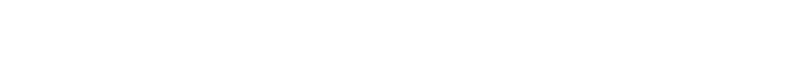

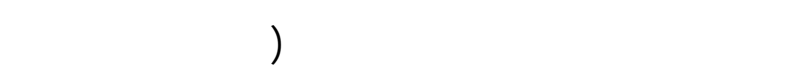

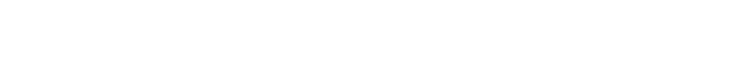

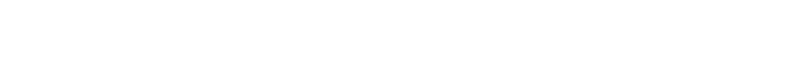
مبلثرة أوغير مبلثرة تصحح فيها الميل ألق صلاحية ف في أغراض للثرب والزراعة والصناعة إلى جان يب تة دهور

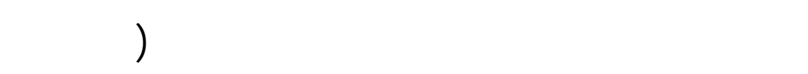

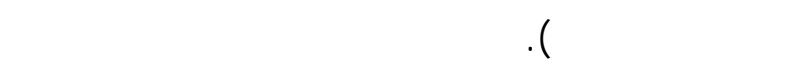
الإنسلن علهسطح الأرض والتي ينتج عنها تغير في تركيز المواد المكونة للهواء بصورة تعتبر ضارة بصحة الإنسلن الإنان

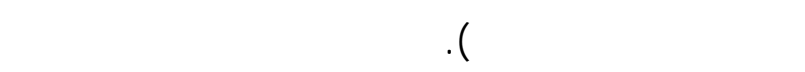
الملوثة ولحة من لكثر الأسبب الجشيوعاَ في نشر الأم ـراض

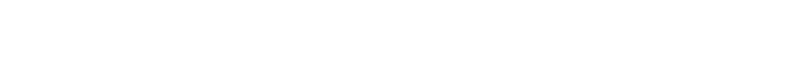
تغير يذكر في طعمه ورائحته ومن هنا كانت خطورتها لُشد الثد 
r -توجد علاقة ارتبطية متعدة بين المتغي -رات الم سنقلة ألمده البحث: مجتمعة وبين الممارست البيئية الخطئة للمبحوثلت في

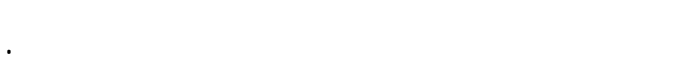

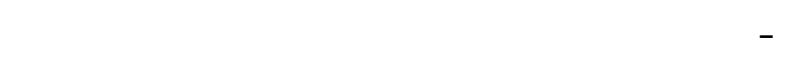

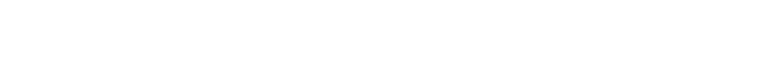
في لَل بُعد من الأبعاد الأربعة المدروسة لكّ عُ على حله.

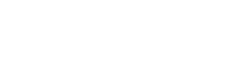

أولاً:مطاقة عينة البهث:

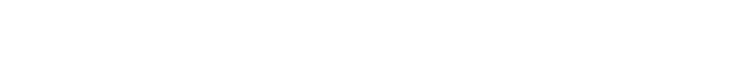

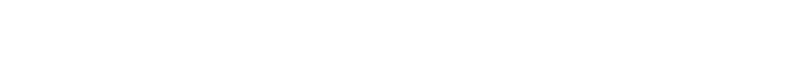
البلحثة مما يسطل عليها التواصل معسكلن المجتمع المحلي، وتحددتشملة هذا البحث في جمبع الريفيت بالقرية وت م حصرهن من خلال حصر عدد الأسر الريفية بالقرية وت م

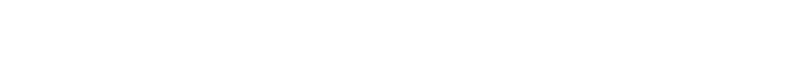
البيانلت من ربة المذزل المسئولة بكل لأسرة. شانياً: أسلوب جمع البيلنات: مُ جمع البيانلت عنطريق المقابلة الشخ صية لأف ـراد

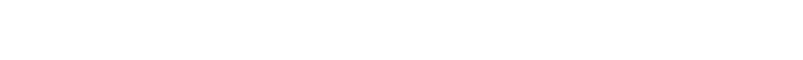
ولختبارها ميدانياً وإعدادها في صورتها النهائية حتى تكون الكنين صالحة لتحقيق أهداف البحث. ثالثاً: المتغيرات البحثية:

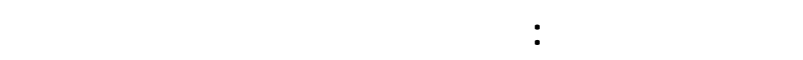

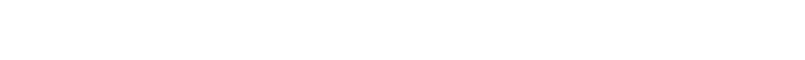

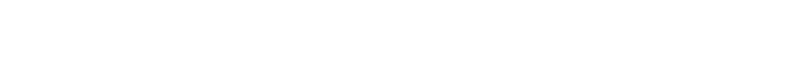

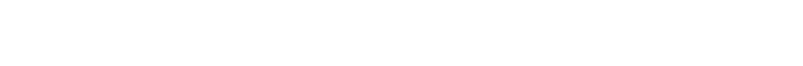
المعيشة، والمشاركة الاجتماعية غير السبمية. المتغير التلع: يمل المتغي _ر الت الع ف ي هـ ذا البح ـاث المماست البيئية الخطئة للمبحوثلت في أربعة أبعاد هـ مي

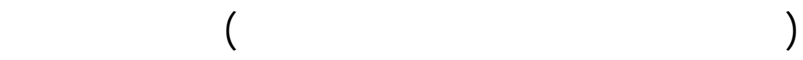

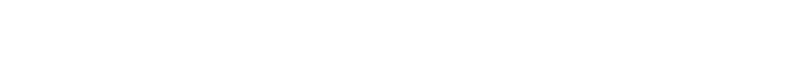

يمهف البحث بصفة رئيسية إل مي درلس ـة المماسس لت البيئية الخلئة للمرلة الريفية وينبقق منه الأهدف الفئية الفرعي ــة التالية: - 20 - n

I - التعرف على مستوى ظبيق المبحوث لت للممابس لت

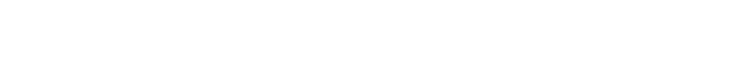
والغذاء، والأرض الزراعية. r - التعرف على توزيع المبحوثلت وفةً لدرجلت الاستجابة لبنود المماسلت البيئية الخطائة في لكل بُعد من الأبعاد الأربعة المدروسة. "ب - درلسة العلاقل الارتبطية بين كل متغير من المتغيرات

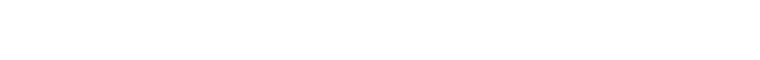

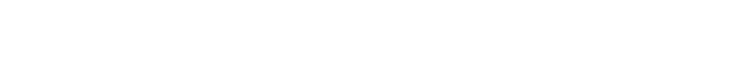
على حله. ع -تحديد العلاقة بين المتغيرات المسنقة المدروسة مجتمعة

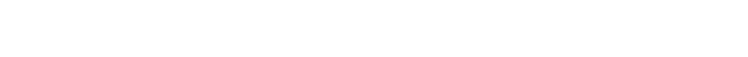

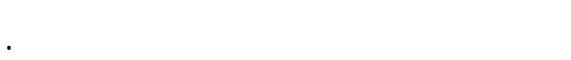
0 - تحديد درجة إسهام كل متغير من المتغيرات الم سنقلة

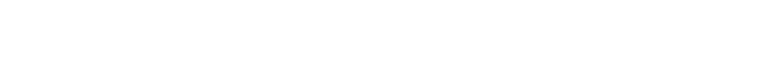
الخلطئة للك بُعد من الأبعاد الأربعة المدروسة. الفروض البحثية: لتقيق الأهدف الثالث والرالع والخلهس ت م صـ ـياغة

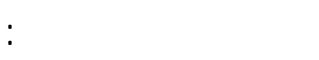
I -توجد علاقة ارتبطية بين كل متغير م ن المتغي -رات المسقلة المدروسة وبين الممارست البيئية الخطئة

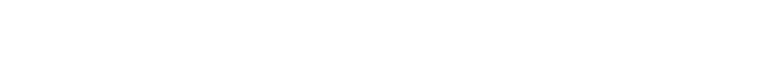

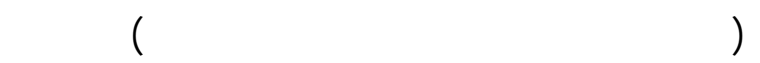
. 


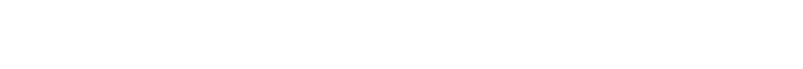

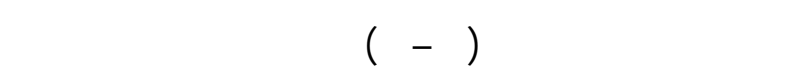

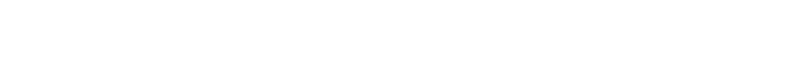

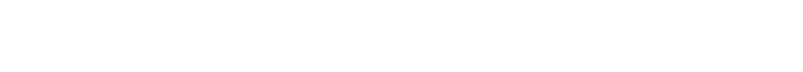

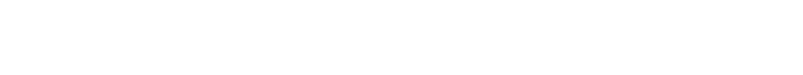

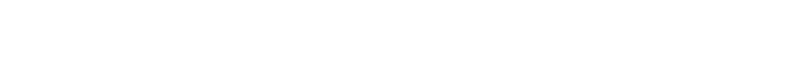

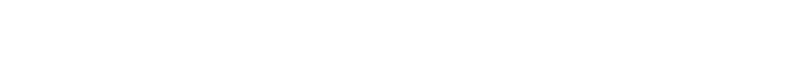
درجة المشاركة الاجتماعية غير الرسمية لهن متوسطة. ثلنيا: الممارسلت البيئية الخلائة اللرفيلت المبحوثلت:

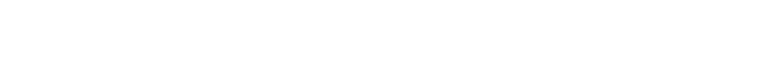

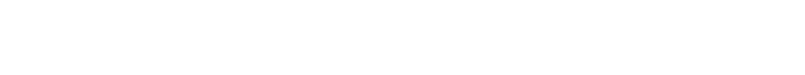
الأربعة المدروسة فيما يلي:

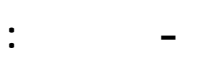

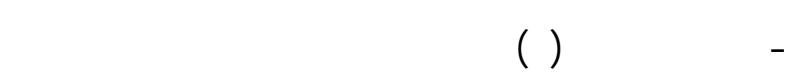
طبيقهن للممارسات البيئية الخلطئة المتعلقة بُبعد الميله،

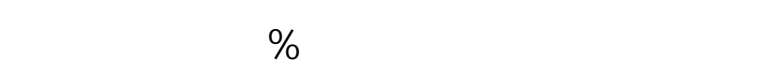

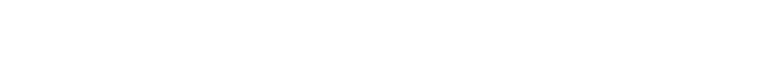

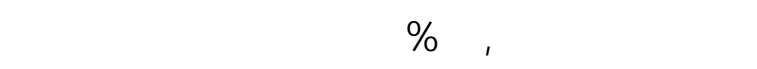

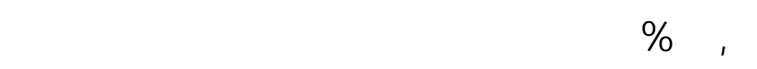

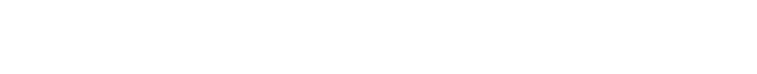

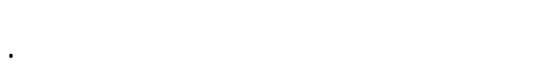

المبحوثة ثلاثة لمستجابت للكل بند من بنود الممارسة إحداها

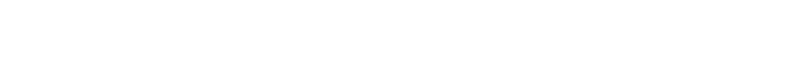

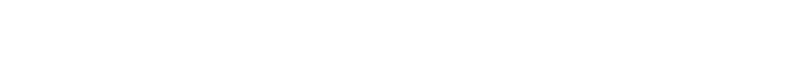

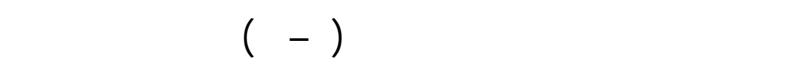

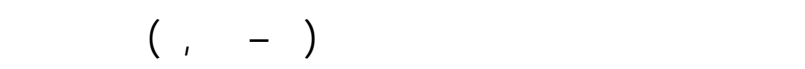

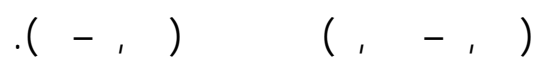
رلبعا: الأساليب الإحصائية:

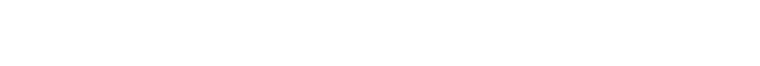

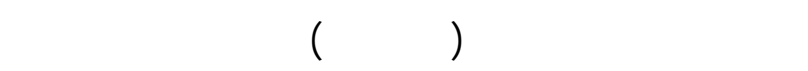

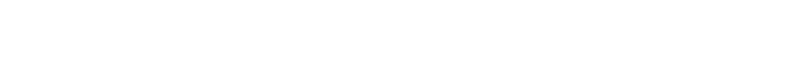

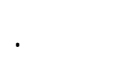

\section{النتائج ومنالثشتها}

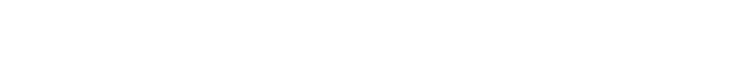
ومناقشاتها فيما يلي: ألواًا: وصف عينة البهث:

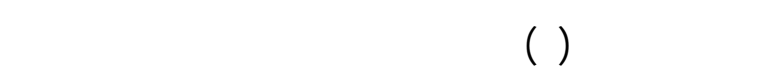

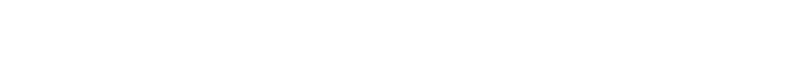

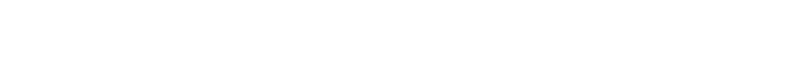

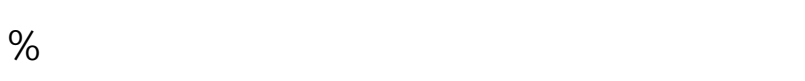
حاصلات علىشهادات تعليمية متوسطة أوجلمعية، وقرلبة

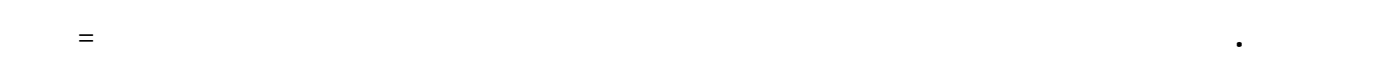

\begin{tabular}{|c|c|c|c|c|c|c|c|}
\hline$\%$ & عدב & الفئل & الخصائص & $\%$ & عدב & الفئلت & الخصائص \\
\hline$\varepsilon १, \mu$ & Vع & منغفض (ع - 7) درجة & 0 & $\mu, \mu$ & Or & القل من سبرسنة & | 1 - عمر \\
\hline$\varepsilon १, \mu$ & Vع & متوسط (V - ( ) درجة & الجغرافي & $\mu, \mu$ & Or & س & المبحوثة \\
\hline $1, \varepsilon$ & $r$ & مررقع (· (1 - זו) درجة & & $r q, \varepsilon$ & $\varepsilon \varepsilon$ & ب جسنة فلكثر & \\
\hline$\varepsilon \Lambda$ & VY & أل aمن - 10 جنيه & 7 - إجمالي الحخل & 1. & 10 & أمية & r ب - الحالة \\
\hline † & $0 \varepsilon$ & 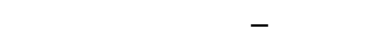 & للشهري لللنسرة & $\varepsilon, 7$ & $\mathrm{~V}$ & تعليم دون المتوبط & التعليمية \\
\hline 17 & $r \varepsilon$ & . . . جنيه فلكثر . & & $\varepsilon \Lambda, V$ & $V^{\mu}$ & شهاةة متونطة & ل لمبحوثة \\
\hline & & & & $\mu 7, \mathrm{~V}$ & 00 & شهاة جلمعِية & \\
\hline $19, \mu$ & rq & منخفض (المل من YV درجة) & V - Vستوى المعيشة & $\mu^{\mu}, \mu$ & ro & صغير (1 -") فرد & 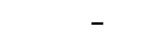 \\
\hline$V V, \mu$ & 117 & متوسط ( ( ) - qع درجة) & & VI, & $1 \cdot V$ & متوسطَ (ع -7) فِرد & أَفراد \\
\hline$\mu, \mu$ & 0 & مرققع ( · درجة فلكثر) & & $0, \varepsilon$ & $\Lambda$ & كبير (V أفراد فلكثر) & الأسرة \\
\hline$\varepsilon, V$ & $\mathrm{~V}$ & منخفض (0 -9) درجة & 1 - المشاركة & $\varepsilon r, 7$ & $7 \varepsilon$ & منخفض (ع -7) درجة & ع -التعرض \\
\hline$O V, \mu$ & 17 & متوسط (· ( -01) درجة & الاجتماعية غير & 07 & $\Lambda \varepsilon$ & متوسط (Y - (q) درجة & الإعلامَ \\
\hline$\mu$ & OV & مرتقع (17 - - r) درجة & الرسمية & $1, \varepsilon$ & $r$ & مرتقع (· - - (1) درجة & \\
\hline
\end{tabular}




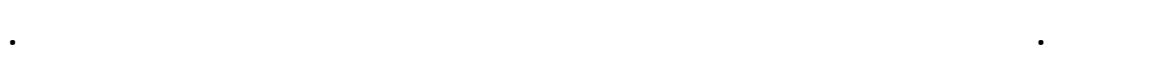

\begin{tabular}{|c|c|c|}
\hline$\%$ & العدد & الفئلت \\
\hline ru & 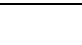 & منخفض (9 -ع |) درجة \\
\hline $77, \mathrm{~V}$ & $1 \ldots$ & متوسط (10 - - (r) درجة \\
\hline $11, \mu$ & IV & مرتقع (rV- TY) درجة \\
\hline $1 \cdots$, & 10 . & المجموع \\
\hline
\end{tabular}

للمنازل في حالة وجوده (

الزراعي بميه الترع (1,7V)

ج ـ - الهلفلت الثنئي ة ولانحدارب ة النم وذج الكال لل

والمختزل بين بهض خصائ المب المبحوثلت والمماوسلت

البيئية الخلائة في جُعد الميله:

يوضخ جدول(ع) معلملات الارتبط البسط ومع لملات

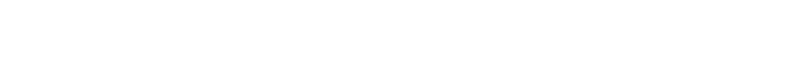
المتعلقة ببعض خصائص المبحوثلت والمماستا البينئية في

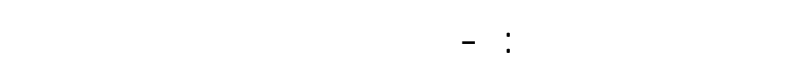

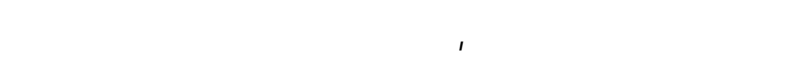
ولجمالي الدخل الشهري للأسرة، ومستوى المعيشة كل على له افراد من جانب وبين المماسلت البيئية الخطئة للمبحوثلت

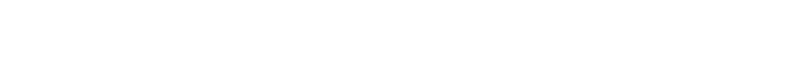

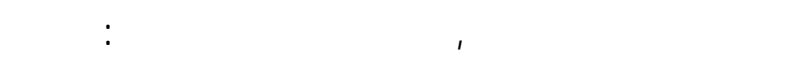

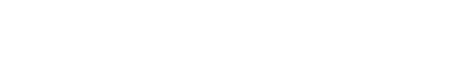

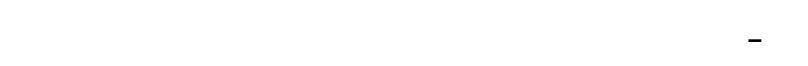

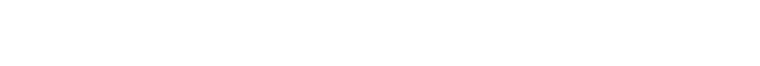

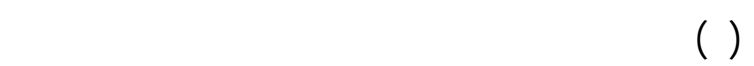

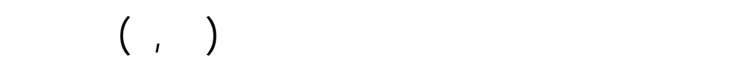
عبوات المبيدات الفارغة في ميل المجاري المائية (1,1)

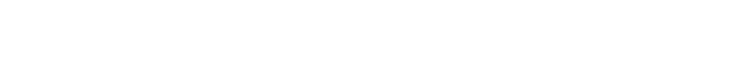

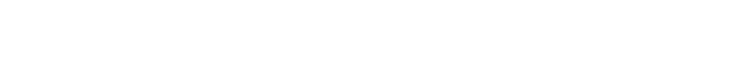

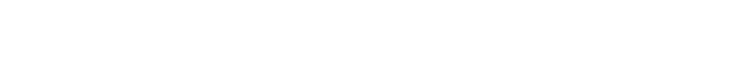

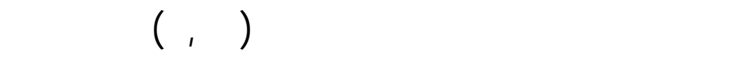

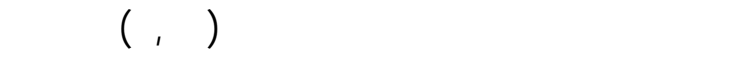
الزيوت المستعملة في المجاري المائية (سو, () وإلق اـاء

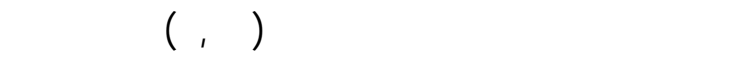
أن هنك ثلاث عبارات ذات متوسط هسابي مرتقع تمل لكثر المماسبت البيئية الخطئة التي نقوم بها المبحوثلت وتؤدي إلي تلوث الميه وهي إهمل صيانة فلاتر الميه

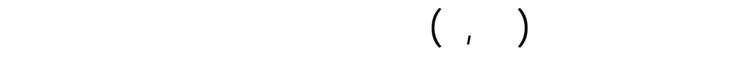

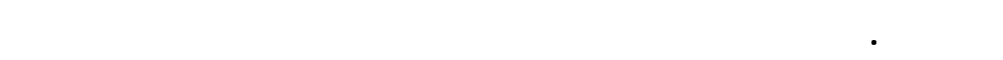

\begin{tabular}{|c|c|c|c|c|c|c|c|c|}
\hline \multirow{2}{*}{ وصفه } & \multirow{2}{*}{ المسلبي } & \multicolumn{2}{|c|}{$\mathbf{y}$} & \multicolumn{2}{|c|}{ ألقانا } & \multicolumn{2}{|c|}{ كأfأ } & \multirow{2}{*}{ 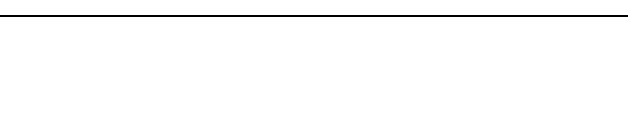 } \\
\hline & & $\%$ & عدב & $\%$ & عدد & $\%$ & عدد & \\
\hline 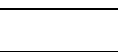 & 1,90 & $1 \cdot, \mathrm{V}$ & 17 & $\Lambda r$ & Irr & $V, \mu$ & 11 & I - إلقاء الحيوانتت والطيور النفقة في الميه \\
\hline منخفض & $1,1 \varepsilon$ & $9 \cdot, \mathrm{V}$ & 147 & $\varepsilon, 7$ & $\mathrm{~V}$ & $\varepsilon, 7$ & $\mathrm{~V}$ & r - غنسل الأولمي والملابس في ميل آلترع \\
\hline مرقع & $r, 7 V$ & $1 \cdot, \mathrm{V}$ & 17 & $11, \mu$ & IV & $\mathrm{V \Lambda}$ & $11 \mathrm{~V}$ & "ب - توصصل ميل الصرف الزرائي بميه الترع \\
\hline a مigu & $\mathrm{I}, \mathrm{\wedge V}$ & 11 & rV & $\mathrm{V} V, \mu$ & 117 & $\varepsilon, 7$ & V & ع - كسح الترششكت المنزلية في مين الترعة \\
\hline منخفض & 1,11 & $\Lambda 7$ & 149 & $9, \mu$ & $1 \varepsilon$ & $\varepsilon, 7$ & $\mathrm{~V}$ & 0 - إلقاء عبوات المبيدات الفارغة ف ي المج اري \\
\hline 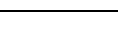 & 1,91 & $\Lambda, V$ & $1 \mu$ & $\Lambda \cdot, 7$ & $|r|$ & $1 \cdot, V$ & 17 & 7 - تقظف ولستحمل الحيولنت في ميل الترع \\
\hline bugia & 1,94 & $10, \mu$ & $r \mu$ & $\mathrm{V} 7, \mathrm{~V}$ & 110 & $\Lambda$ & ir & V - إلقاء الزيوت المستعملة في مجاري الميل \\
\hline مرنقع & $r, 71$ & $14, \mathrm{~V}$ & 19 & 17 & re & $V 1, \mu$ & $1 \cdot V$ & 1 - إهمل تيظفي الخزان العلوي للمنازل في حالة \\
\hline مرتقع & $r, \varepsilon l$ & $1 \cdot, \mathrm{V}$ & 17 & $r q, \mu$ & $\varepsilon \varepsilon$ & 7 . & 9. & 9 - إهمل صيانة فلاتر الميه بصورة دورية \\
\hline
\end{tabular}




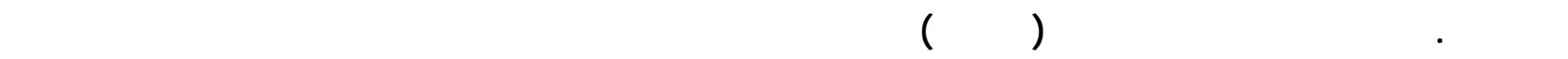

المبحوئت والممارسلت البيئية في بُمد الميله

\begin{tabular}{|c|c|c|c|}
\hline معالم الانحدار الجزئز المعياري & المعوذج الكالل & معالل (بيرسنبهن) البسيط & المتغيرات المسقلة \\
\hline & $\cdot, \cdot \mathrm{V} \cdot$ & $\cdot, 1 \cdot 7$ & عمر المبحوثة \\
\hline & $\cdot, \cdot \Lambda$. & $\cdot, \cdot \Lambda \Lambda$ & الحالة التعليمية للمبحوثة \\
\hline & $\cdot \cdot \cdot 7 r$ & $* \cdot, I \vee 7-$ & عدد أفراد اللَّدرة \\
\hline & $\cdot, \cdot r \mid$ & $* \cdot, 1 \wedge 7-$ & التعرض الإعلامي \\
\hline **., r०१- & **., rา & **., YOH- & الافتاح الجغرافي \\
\hline$* * ., \varepsilon \cdot 1-$ & **., ए๘१- & $* * ., \varepsilon \cdot 1-$ & إجمالي النخل للشهري للأسررة \\
\hline & $\cdot, \cdot \mathrm{rq}$ & $* *,, r \wedge \mu-$ & مستوى المعيشة \\
\hline & $* \cdot, \mid \varepsilon r-$ & $* \cdot, I V \mathcal{E}-$ & المشارِكة الاجتماعية غير الرسمية \\
\hline$\cdot, \varepsilon V I$ & $\cdot, 0 \cdots$ & & معلطل الارتبط المتعدد R R \\
\hline$\cdot$ & $\cdot$ ro. & & معلمل التحصيد R2 \\
\hline$* * r \cdot, 797$ & $* * 0, \Lambda \cdot \mu$ & & ق قيمة F \\
\hline
\end{tabular}

الجغرافي، وربما يمكن فسير ذك أنه بزياة نخل الأس -رة

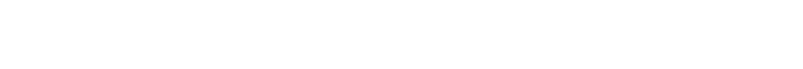
ممارسة الأنثطة البيئية بشكلسليم.

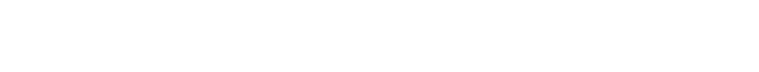

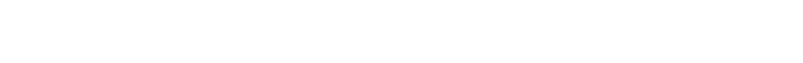

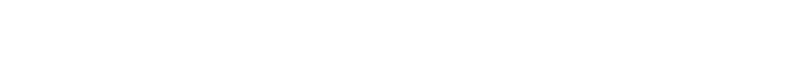

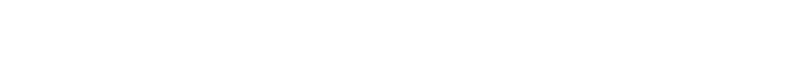

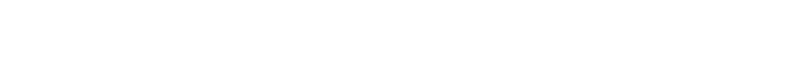

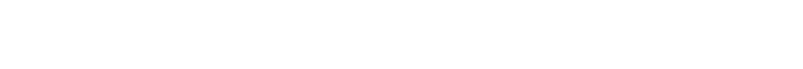

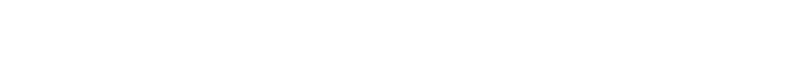

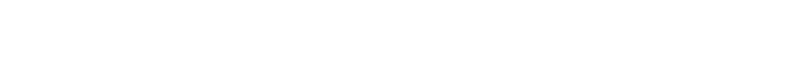
بصورة دورية. ونل الممارسك البيئية الخطائة للريفيك المبحوثت في

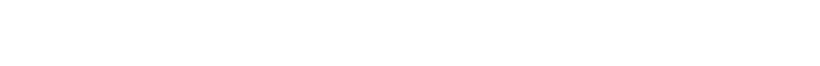
للإعلام، ويشاركن مشاركة لجتماعية غير بسمية، ول حيين

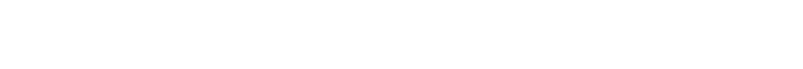
ومستوى المعيشة المرفقع أيضاً.

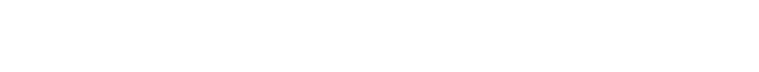

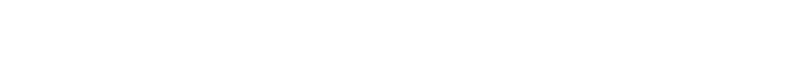

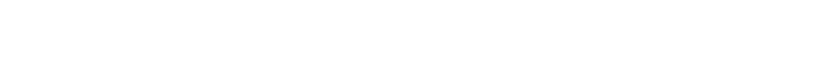

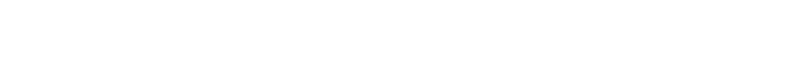

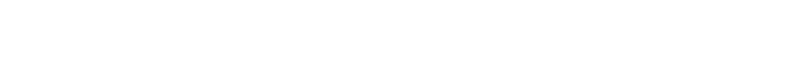
المعيشة والنعرض الإعلامي وعدد أفراد الأسرة والمشاركة الاجتماعية غير الرسمية تمل الممارست البيئية الخطائة لهن الهن في بُعد الميل. كما ويبين نفس الجدول المالق أن المتغيرات الم عسقلة

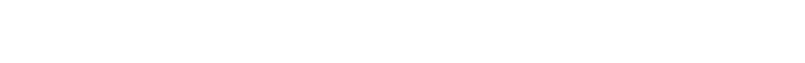

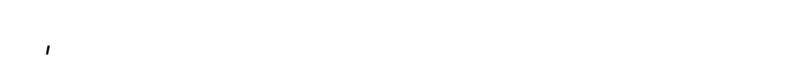

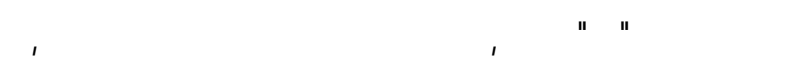

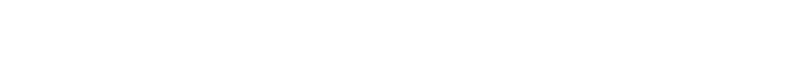
المتغيرات المسقلة مجتمعة وبين الممارسكت البيئية الخطائة

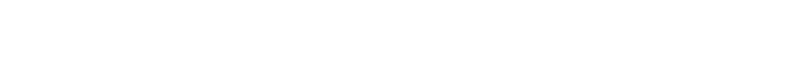

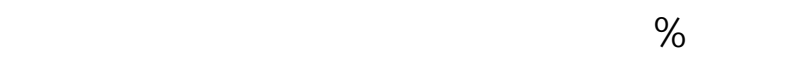

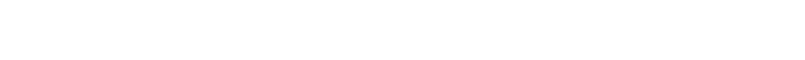

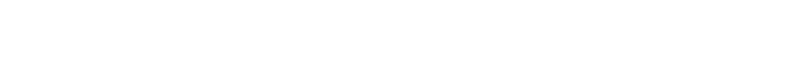

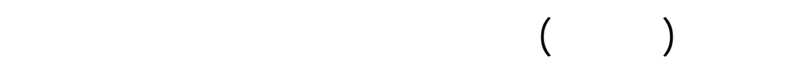

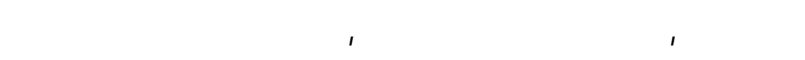

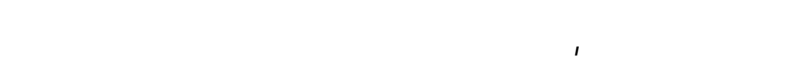

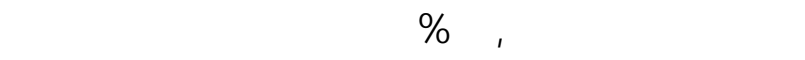
هما على الترتيب إجمالي الذخل اللشهري للمٔسرة، والافتناح 
وإقاء الطيور الميتة ومخلفلت الذبح في الطريق (عَ, I)

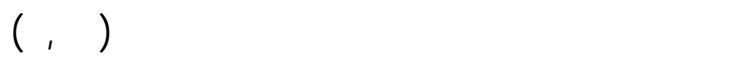

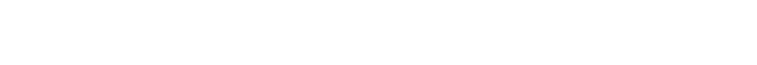

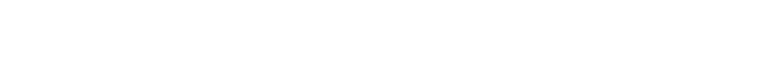

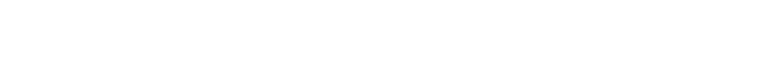

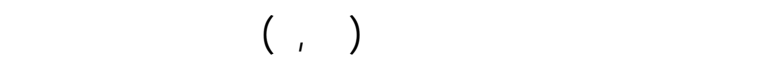

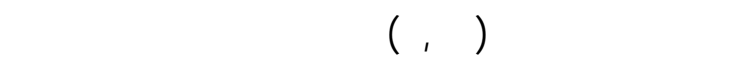

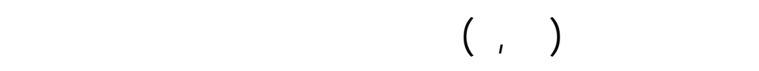

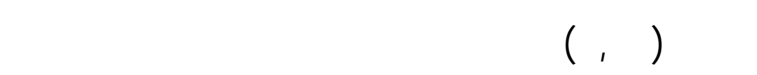

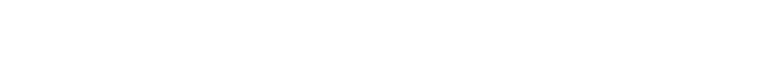
التي ققوم بها المبحوثثت وتؤدي إلي تلوث الهواء وهي

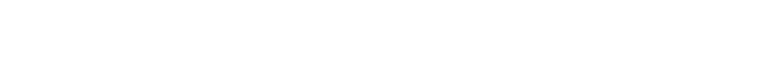
لأغراض الطهي (r,OV) ولستخده الشعلة (الكيروسين الثنان والغاز) لطهي الطعلم ف مي الأم لكن المغلق ـة (r,71) وحرق المخلفت المذزلية والقملمة (r,TV).
يدل على أصالة هذلن المتغيران في تق سير التب اين ف يي الممارست البيئية الخلطئة للاريفيت في هذا البُعد.

\section{r - بُّد الهواء:}

أ - يعرض جدول(0) توزيع المبحوث لت وفة ألم ستوى

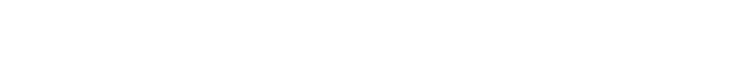

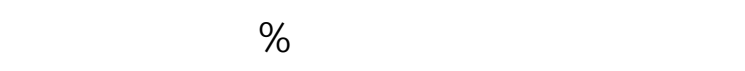

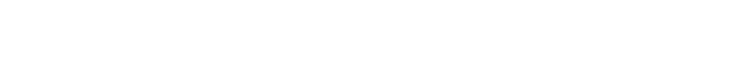

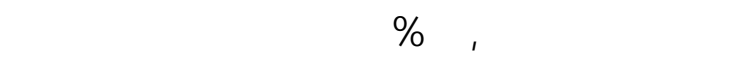

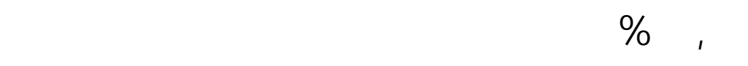

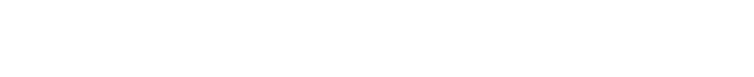
الخلئة في هذا البُعدمتوسط أومريقع.

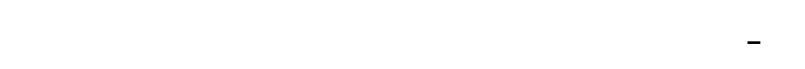

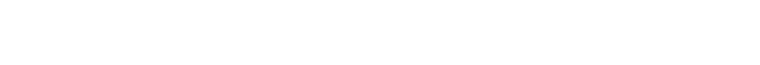
(7) أن العبارات ذات المتوسط المسابي المنخغض وهي إقلمة كمائن الطوب أوالفح م وس ط المن المن ازل

جطل 0. توزيع المبحوثلت وقةاً لمستوى شلبيقهن لاممارسك الخلائة في جُّد الهواء.

\begin{tabular}{|c|c|c|}
\hline$\%$ & العد & الفئلت $\quad$ الم \\
\hline$r$. & $\mu$ & منخفض ( · -17) درجة \\
\hline $71, \mu$ & 9ץ & متوسط (IV - IV) درجة \\
\hline $\mathrm{I} \Lambda, \mathrm{V}$ & rA & مرتقع (ع - - ب) درجة \\
\hline $1 \cdots$, & 10 & المجموع \\
\hline
\end{tabular}

جرط 1. توزيع إجلبلت المبحوثلت وقاً لممارساتهن لبنودف بُمد الهواء

\begin{tabular}{|c|c|c|c|c|c|c|c|c|}
\hline \multirow{2}{*}{ وصفه } & \multirow{2}{*}{ المرجح } & \multicolumn{2}{|c|}{$\boldsymbol{y}$} & \multicolumn{2}{|c|}{ أحيلناً } & \multicolumn{2}{|c|}{ دأما } & \multirow[t]{2}{*}{ 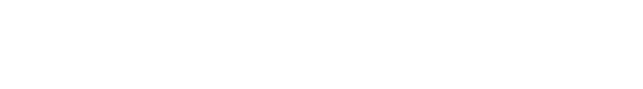 } \\
\hline & & $\%$ & عدב & $\%$ & عدد & $\%$ & عدد & \\
\hline 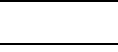 & $r, 7 V$ & $1 \cdot, \mathrm{V}$ & 17 & $11, \mu$ & IV & $\mathrm{V} \Lambda$ & $11 \mathrm{~V}$ & I - حرق المخلفلت المذزلية والقملمة \\
\hline a a & $\mathrm{I}, \mathrm{\Lambda V}$ & $r$. & $\mu$. & $V^{\mu}, \mu$ & 11. & $7, V$ & 1. & r - حرق مخلفل المحاصبل الزراعية \\
\hline 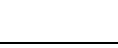 & $1, r \varepsilon$ & $\Lambda 0, \mu$ & 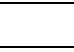 & $\varepsilon, 7$ & $\mathrm{~V}$ & $1 \cdot$ & 10 & "ب - إلقاء الطيور المينة ومخلفات الذنح في الطريق \\
\hline منخفض & $1, r V$ & $\mathrm{~V} \wedge, \mathrm{V}$ & 111 & $10, \mu$ & $r \mu$ & 7 & 9 & ع - إقُلمة مزارع الدولجن ويط الكتلة للسّكنية \\
\hline منخفض & $1, \Gamma \mu$ & $\Lambda \varepsilon$ & $1 \pi 7$ & $9, \mu$ & $1 \varepsilon$ & $7, V$ & $1 \cdot$ & 0 - إقلمة كمائن الطوب أو الفهم وبط المنازل \\
\hline متوبط & $1,9 \mu$ & $1 \varepsilon$ & rI & $\mathrm{V} \Lambda, \mathrm{V}$ & 111 & $\mathrm{~V}, \mu$ & 11 & 7 - لستخددd بقايا النباتلت الجلفة كوقود اللتفئة \\
\hline مرقع مع & $\mathrm{r}, \mathrm{OV}$ & $9, \mu$ & $1 \varepsilon$ & $r \varepsilon$ & $\mu 7$ & $77, V$ & $1 \cdots$ & 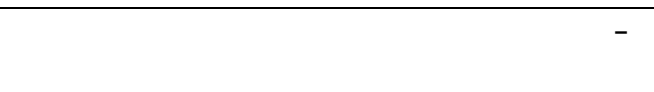 \\
\hline مرقعع - مرع & $r, 71$ & $\Lambda$ & Ir & r & & $79, \varepsilon$ & $1 \cdot \varepsilon$ & 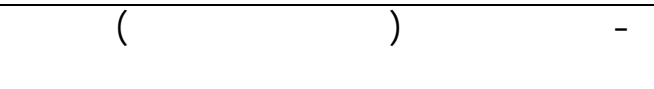 \\
\hline متوسط & $1, \Lambda \Lambda^{\mu}$ & $r 0, \mu$ & ب & $77, \mathrm{~V}$ & $1 \cdots$ & $\Lambda$ & Ir & 9 - الزخلن النانج مـ ـن ح ـرق ف ـضلات الأطعه ـة \\
\hline متوسط & $r, \cdot 1$ & $1 \cdot, \mathrm{V}$ & 17 & $\mathrm{VV}, \mathrm{r}$ & 117 & 14 & 11 & · I - تكوم روث المولثي بجوار المذزل \\
\hline
\end{tabular}




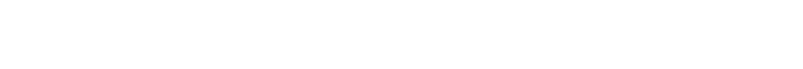

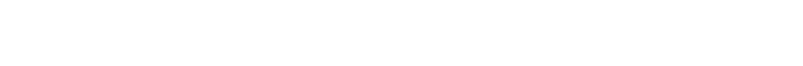

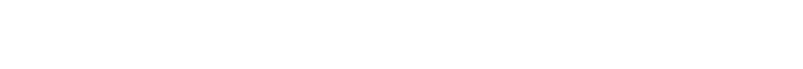

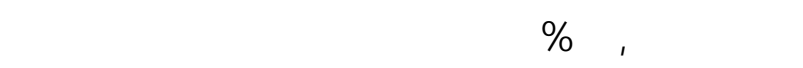

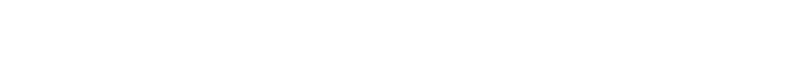

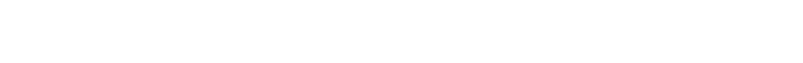

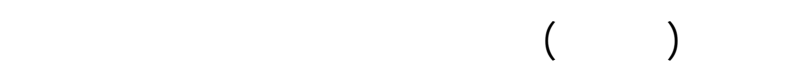

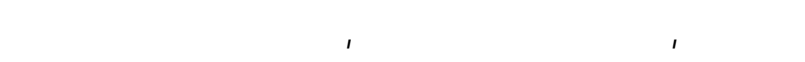

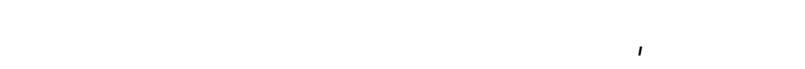

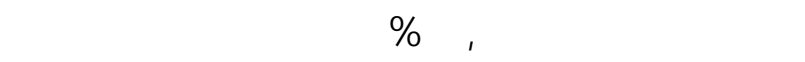

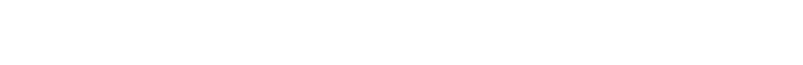

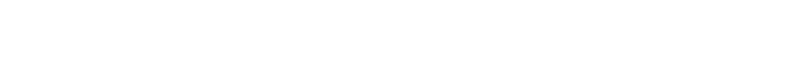
المعيشة، وعدد أفراد الأنسرة.

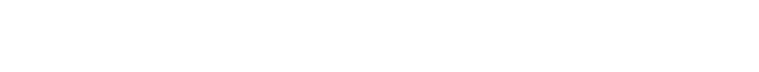

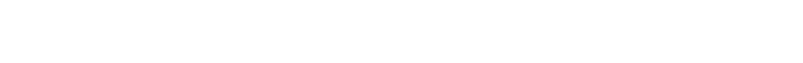

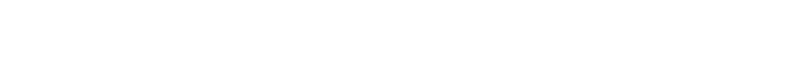

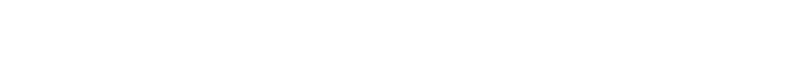
ويط المنازل، وإلقاء الطيور الميية ومخلفت الـ نيح ف ي الطريق، ونط

\section{ج ـ - الللافلت الثنائي ة ولانحدارب a الله وذج الكال ل ل والمختل بين بصن خصائص المبحوثلت والممارسلت البيئية الخلائة في بُمد الهواء:}

يوضغ جدول(V) معلملات الارتبط البسيط ومع الملات

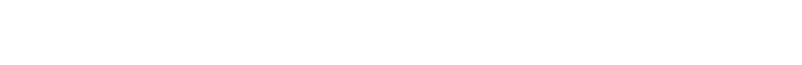

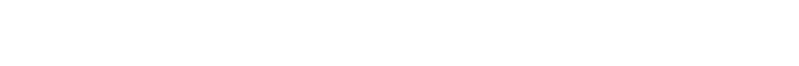

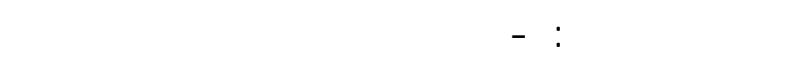

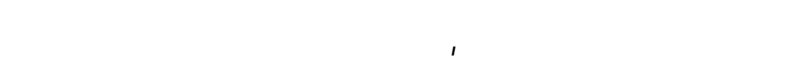

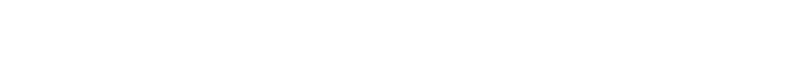

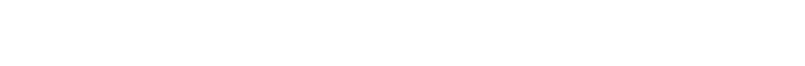

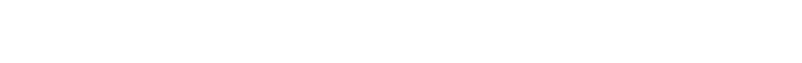

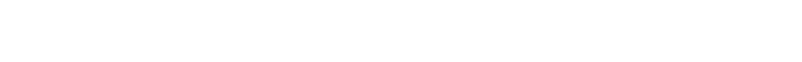
ومعنوية عند مستوى 0 ·, · بينه وبين ومستوى المعي ششة.

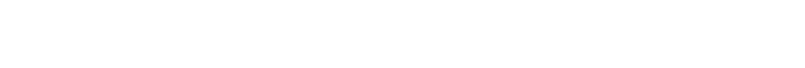
الممارست البيئية الخطائة لهن في مُبد الهواء الهماء. كما ويبين نفس الجدول للسابق أن المتغيرات الم ستقلة المباء المدروسة مجتمعة ترتبط بالممارس لت البيئي ـة الخطائة

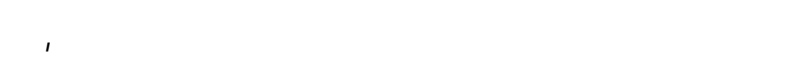

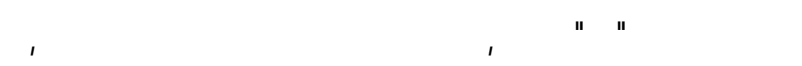

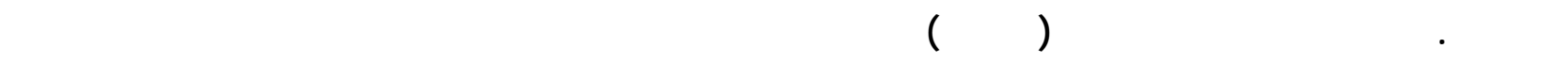

\begin{tabular}{|c|c|c|c|}
\hline معلل الانحدار الجزئي المعياري & النمعذج الكالل & معالل لالارتبلا البسيال & المغغيرلت المسقلة \\
\hline & $\cdot, 1 \% 0$ & $\cdot, I \cdot r$ & عمر المبحوتة \\
\hline & $* \cdot, \mathrm{IVY}-$ & $\therefore .19$ & الحالة التعليمية المبحوثة \\
\hline$* \cdot, 10 \mathrm{r}$ & $\cdot, 1 \mu \mu-$ & 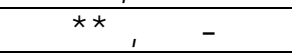 & عدد أَفراد الُّْرةرة \\
\hline & $\cdot, I \mu^{\mu}$ & $* *,$, Y AV- & التعرض الإعلامي \\
\hline$* * \cdot, \mu \cdots$ & $* * \cdot, \mathrm{\mu} \cdot \mathrm{V}-$ & **., \%११- & الاففتاح الجغرافي \\
\hline 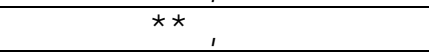 & $* * ., \varepsilon\urcorner \varepsilon-$ & 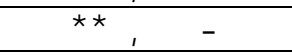 & إجمالي النخل للشهري للمُسرة \\
\hline **.,YYA- & **, YYMA- & $* \cdot, 199-$ & مستوى المعيشة \\
\hline$* * \cdot, Y \mu \cdot-$ & **.,YAY- & $* * \cdot$, หา & المشاركة الاجتماعية غير الرسمية \\
\hline$\cdot, 7 \cdot \varepsilon$ & 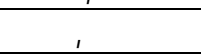 & & م R الارتبط المتعدد \\
\hline$\cdot, \mu 70$ & $\cdot, 499$ & & R2 معل التحييد \\
\hline$* * \mid 7, \mathrm{rol}$ & 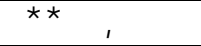 & & ق قيمة F \\
\hline
\end{tabular}


(9) أن العبارات ذات المتوط المسابي المنخفض وهي

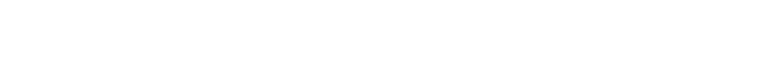

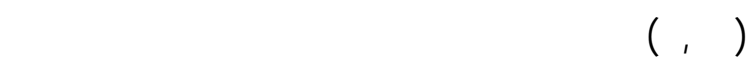

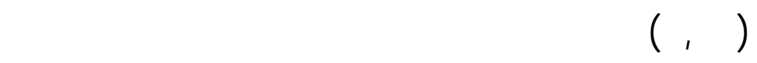

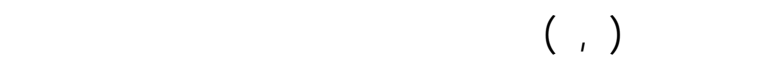

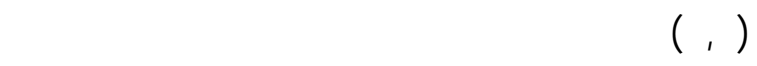

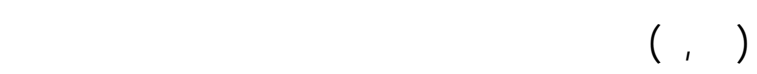

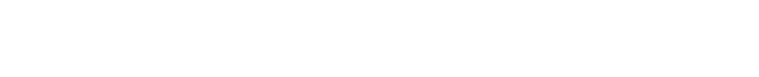

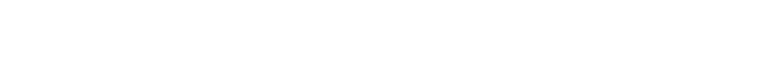

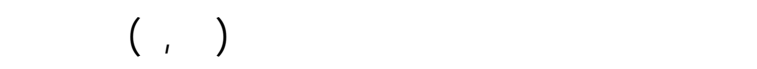

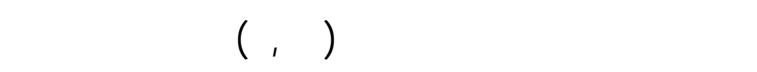

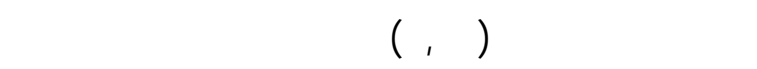

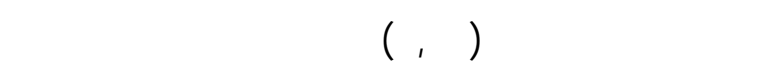

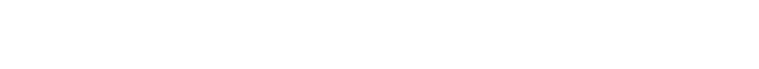
التي قوم بها المبحوثلت وتؤدي إلي تلوث الأغنية وهما

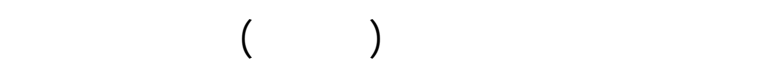

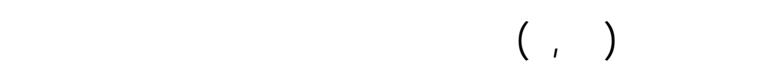
الطهي (r,V

\section{ج - - الملفلت الثنائي ة والنحدارب ة للنم وذج الكال لل} والمختزل بين بهض خصائ المص المبحوثلت والمماوسلت البيئية الخلائة في بُعد الغذاء:

توضح بيانتا جدول( · (1) معلملات الارتب لط الب سيط

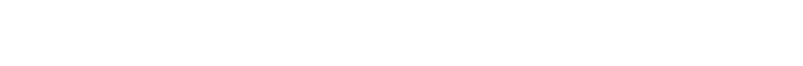

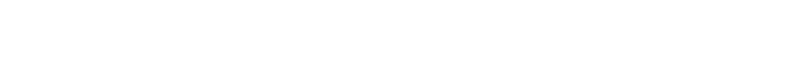
والمماسلت البيئية في بُعد الغذاء، وتبين منه:
وأن لَذثر المماست الخطلئة للمبحوثلت في هذا الُبعد هـ ي

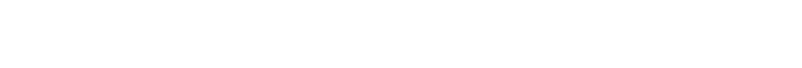
(الكيروسين والغاز) لطهي الطعل في الأملكن المغلقة. ومثل المماست البيئية الخطئة للاريفيت المبحوثلت في

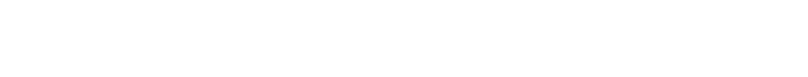

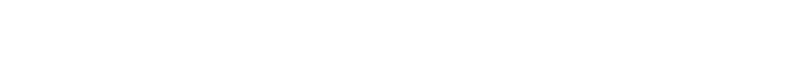

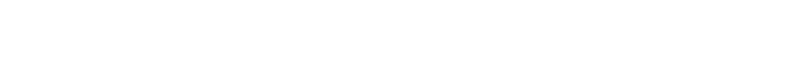
الرسمية. كما تبين أن متغيرات عدد أف ـراد الأس ـرة، والافة ـاح

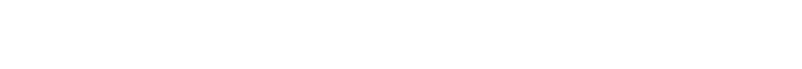

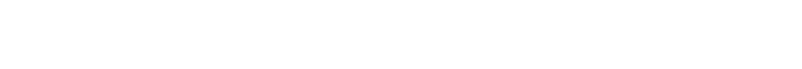

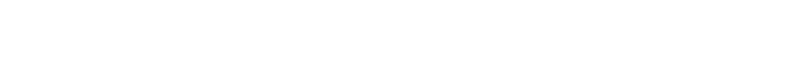
بالنبة لُبعد الهواء مما يدل على أصالة هذه المتغير التغيرات في في

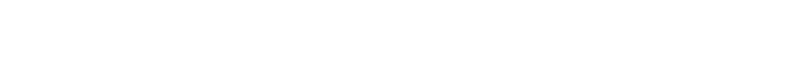
هذا البُعد.

\section{r - بُعد الغذاء:}

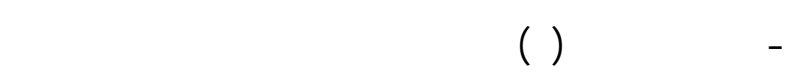

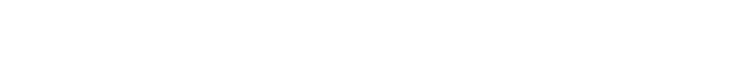

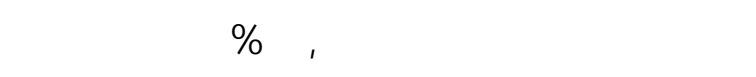
مستوى قطبيقهن للمماسبت الخطائة في بُع دم الغ ـذاء منخفض، و07,V\% في المستوى المتوسط، وعليه ف إن

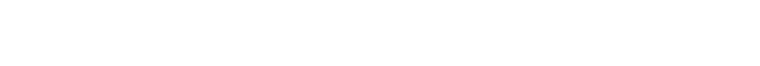
المتوسط للمماسست الخطائة في هذا البُعد.

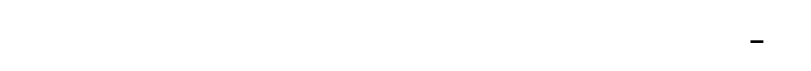

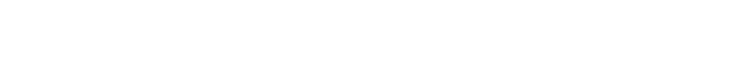

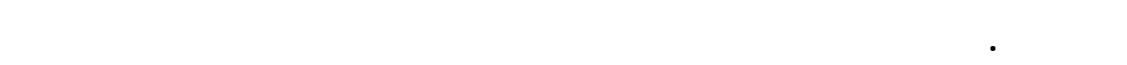

\begin{tabular}{|c|c|c|}
\hline$\%$ & 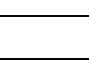 & الفئلت \\
\hline$\varepsilon \mu, \mu$ & 70 & منخفض (IV- II) درحة \\
\hline $07, V$ & 10 & متوسط (1) -רץ) درجة \\
\hline صفر & صفر & مرقع (YV - بץ) درجة \\
\hline $1 \cdots$, & 10 & المجموع \\
\hline
\end{tabular}


جدط 9 . توزيع إجلبلت المبحوثلت وقّاً لممارسلتهن لبنودف بُمد الغذاء

\begin{tabular}{|c|c|c|c|c|c|c|c|c|}
\hline \multirow[b]{2}{*}{ وصفه } & \multirow{2}{*}{ الهسالي } & \multicolumn{2}{|c|}{$\mathbf{y}$} & \multicolumn{2}{|c|}{ أحيلناً } & \multicolumn{2}{|c|}{ دأ. } & \multirow[b]{2}{*}{ العبارك } \\
\hline & & $\%$ & عدد & $\%$ & عدב & $\%$ & عدב & \\
\hline مرقع & المريح & $7 v$ & 1. & $\mu^{\mu} \mu$ & $r$. & $\Lambda$. & Ir. & 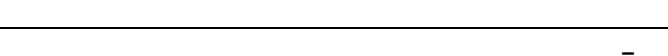 \\
\hline متوقط & $r, 1$. & $\frac{14}{14}$ & 11 & 77 & 99 & $r r$ & r & r - لمتخدd الزت للقل لكثر منمرة \\
\hline متهمط & r,ro & $11, \mu$ & IV & or, & V9 & ب7 & $0 \varepsilon$ & بـ - غسل الخضروات الورقة ددون لستخده الخل \\
\hline مت متوط & $1, \Lambda 1$ & $\mathrm{ro}, \mathrm{\mu}$ & $\mathrm{OH}^{\mu}$ & $\varepsilon \Lambda$ & Vr & $17, \mathrm{~V}$ & ro & ع - حنظ الأطعة في أولي الألومونيوم \\
\hline متوطط & $\mathrm{I}, \mathrm{V} \wedge$ & $\varepsilon r$ & $7 \mu$ & $\mu \wedge$ & OV & $r$. & $\mu$. & 0 - عنم لستبعاد الرلس والَّأُشاء الدلخلية للسمك عند \\
\hline منغفض & $1, \mu$. & $\mathrm{V} 7$ & $11 \varepsilon$ & 11 & rV & 7 & 9 & 7 - وضع المقليت على ورق الجرائد \\
\hline منخفض & $(1, \mu)$ & $\mathrm{VV}, \mu$ & 117 & IE & r) & $\Lambda, \mathrm{V}$ & $1 \mu$ & V - لمتخده مواقد الطب والنشت في الطه \\
\hline مرتقع & $r, 0 V$ & $11, \mu$ & IV & $r$. & $\mu$. & $7 \Lambda, V$ & $1 \cdot \mu$ & ^ - لمتخده المبيدات الحشرية (البودرة) لحظظ الغلال \\
\hline منخفض & $1, \mu$. & $\mathrm{V} \Lambda, \mathrm{V}$ & 111 & $\operatorname{lr}$ & 11 & $9, \mu$ & $1 \varepsilon$ & 9 - إضضافة مكسبت الطعم عن ـد ص ـناعة المربـ لت \\
\hline 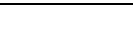 & $1, r \varepsilon$ & $\Lambda 1, \mu$ & Irr & $1 \mu, \mu$ & $r$. & $0, \mu$ & $\Lambda$ & • ا -شرراء الأغنية المكشوفة من الباعة الجائلين \\
\hline منخفض & $1, r \mu$ & $\Lambda 1, \mu$ & ITr & $I \varepsilon, V$ & r & $\varepsilon$ & 7 & 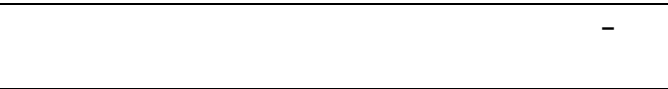 \\
\hline
\end{tabular}

\begin{tabular}{|c|c|c|c|}
\hline معالل الانحدار الجزئل المعياري & المعوذج الكالل & معالم (بيرسنبلا البسطا & المتغيرلت المسقلة \\
\hline & . YV & .10 & عمر المححوثة " \\
\hline **. & **., rq\- &., $1 \mu 0-$ & الحالة التعلمبة للمبحوثة \\
\hline & $\cdot, \cdot\urcorner \varepsilon$ & $\cdot ., 9 \mathrm{~V}$ & عدد أُفراد الَأُسرة \\
\hline$* *, r \wedge 0$ & $* * \cdot, 19 \mathrm{~V}$ & **., r90- & التعرض الإعلاهي \\
\hline$* \cdot, 1 \wedge \cdot-$ & $* * \cdot, r \cdot \varepsilon$ & **, rOV- & الافتاح الجغرافي \\
\hline & **., rq & **, YIIT- & إجمالي النخل للثهري للأنسرة \\
\hline & $\cdot, r \Upsilon 9$ & $\cdot, \cdots \varepsilon$ & مستوى المعيشة \\
\hline & $\cdot ., 99$ & $\cdot, \cdot \wedge \varepsilon$ & المشاركة الاجتماعية غير الرسمية \\
\hline$\cdot, \mu 70$ & $\cdot, \varepsilon \wedge \varepsilon$ & & معلمل الارتبط المتعدد R \\
\hline ( & - זMO & & معلطل التحصيد R2 \\
\hline$* * V, \mu \wedge$. & $* * 0, \mu \uparrow q$ & & G قيمة F \\
\hline
\end{tabular}

كما ويبين نفس الجدول للسابق أن المتغيرات الم سسقلة

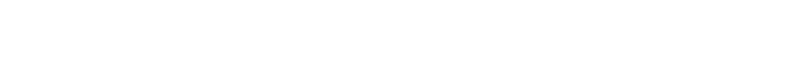

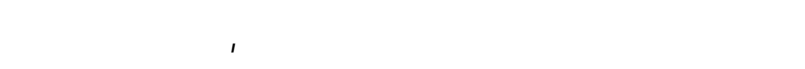

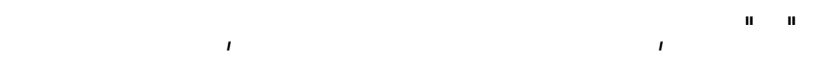
القول بوجود علاقة ارتبطية متعددة بين المتغيرات المسنقة

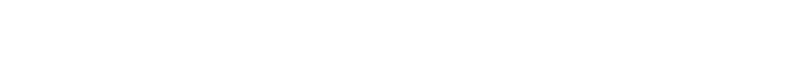

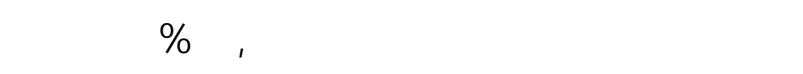

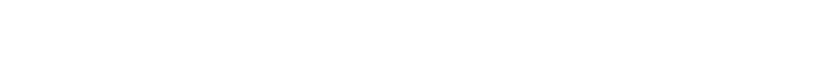

I - وجود علاقة ارتبطية عكسية ومعنوية عند مستوى

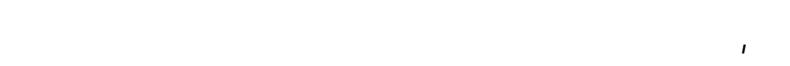

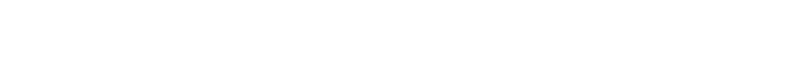

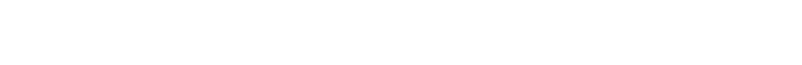

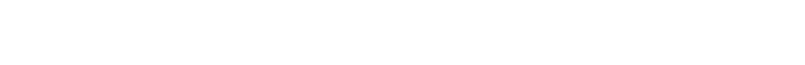

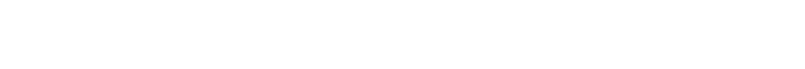
المماوسلت البيئية الخطائة في بُعد الغذاء. 
فهير التباين في الممارست البيئية الخطائة للريفيك ف مي

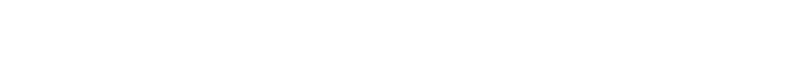

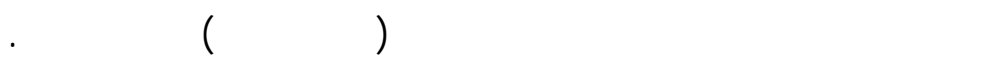

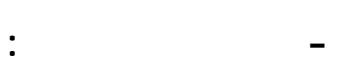

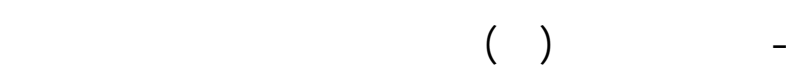

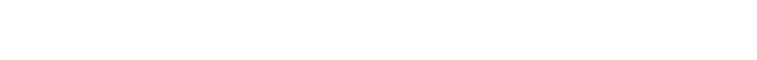

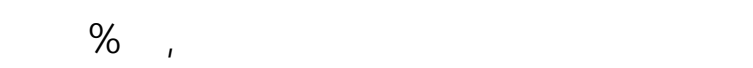
المبحوثثت مستوى ظبيقهن للممارست الخطائة في بُعد

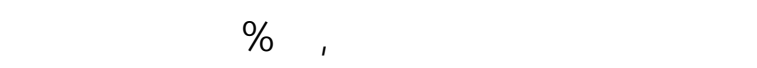

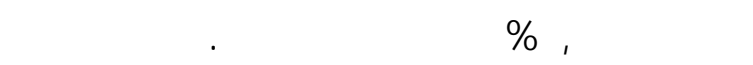
يقرب من ثلثي العينة مستوى طبيقهن للمماوسات ف في هذا البُعد متوبط.

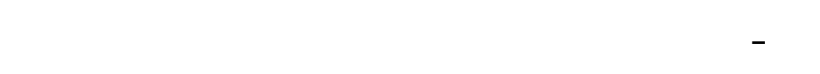

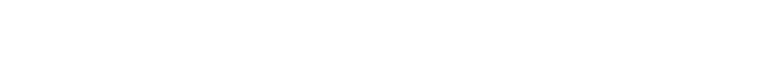

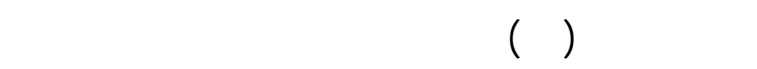

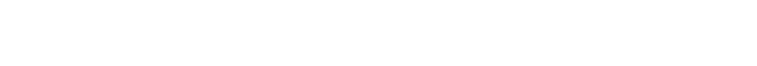

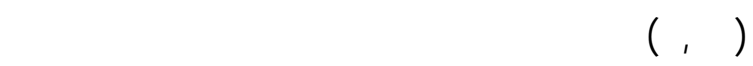

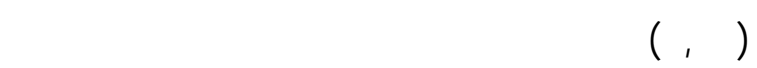

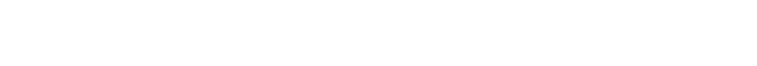
المبحوثلت بدرجة متوططة وهما الإسراف في لمتنخدله

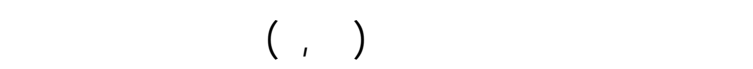

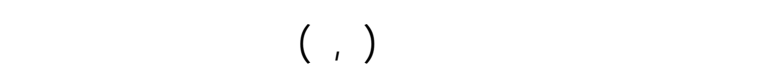

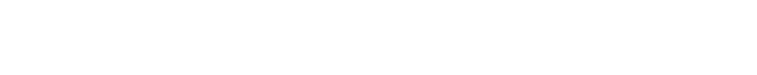
الممارسات التي قوم بها المبحوثلت وتؤدي إلي تنا _وث

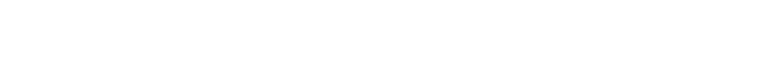

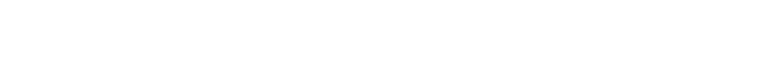

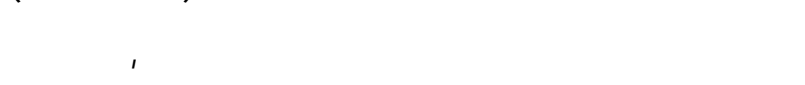

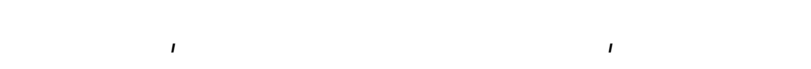

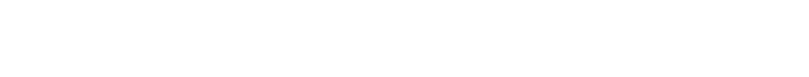

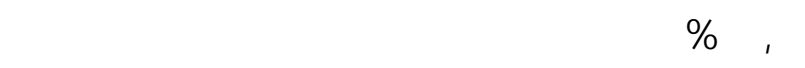

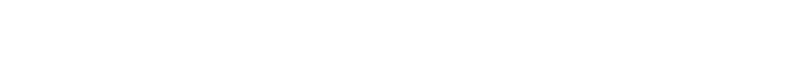

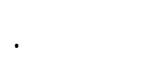

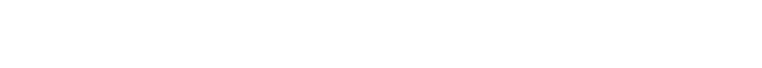

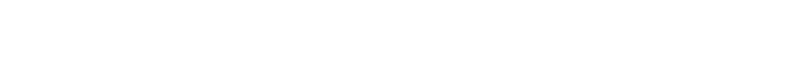

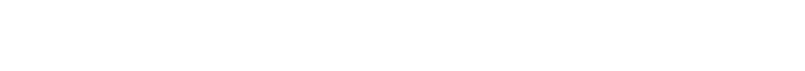

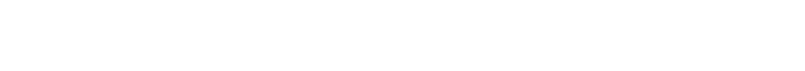
بالفريزر، وشراء الأغنية المكشوفة من الباعة الجائلين، وأن

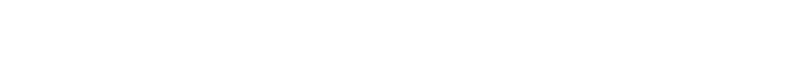
لستخدل أولفي الألومونيوم في الطهي ، ولستخدلم المبيدات

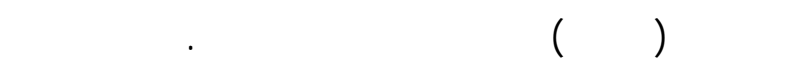

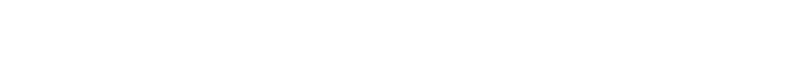

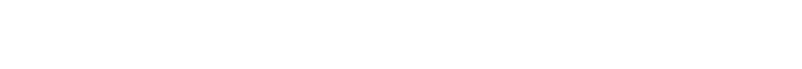
أسروهن. وفظل الممارسك البيئية الخطائة للريفيت المبحوثات في

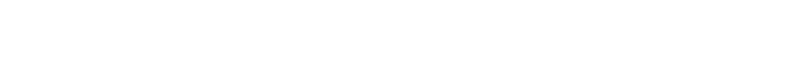
الجغرافي، وإجمالي النخل الشهري للمأسرة.

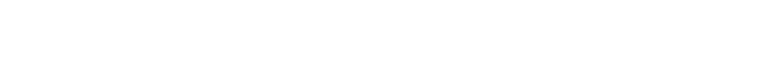

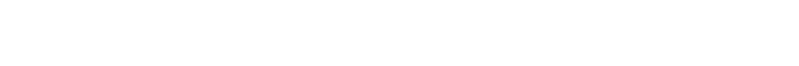

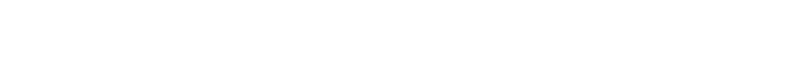
والمختزل مما يدل على أصالة هذه المتغيرات الثلاثة في في

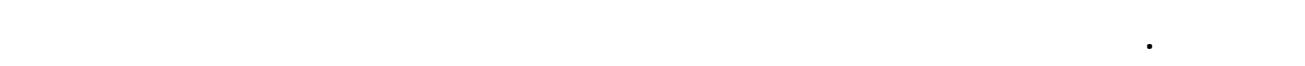

\begin{tabular}{|c|c|c|}
\hline$\%$ & العدد العد الع & الفئلت \\
\hline$\mu \mu, \mu$ & 0. & منغضض (7 -9) درجة \\
\hline $70, \mu$ & 91 & متوطط ( - 1 -عا) درجة \\
\hline $1, \mu$ & $r$ & مرنقع (10 -1 (1) درجة \\
\hline $1 \cdots$, & 10. & المجموع \\
\hline
\end{tabular}


جدط r ا . توزيع إجلبلت المبحوثلت وقَّاً لممارسلتهن لبنود بُجد الأرض الزراعية.

\begin{tabular}{|c|c|c|c|c|c|c|c|c|}
\hline \multirow{2}{*}{ وסفه } & \multirow{2}{*}{ المسلبع } & \multicolumn{2}{|c|}{$y$} & \multicolumn{2}{|c|}{ كجيلاً } & \multicolumn{2}{|c|}{ داكما } & \multirow{2}{*}{ المبارلت } \\
\hline & & $\%$ & عدد & $\%$ & عدد & $\%$ & عدد & \\
\hline متوبط & $1, \wedge 9$ & $\overline{r l, \mu}$ & $\mu r$ & $7 \Lambda, V$ & $1 \cdot \mu$ & 1. & 10 & 1 - اللئبرافية في لمد تخدلم الأنس مدة والمبي دات \\
\hline
\end{tabular}

\begin{tabular}{|c|c|c|c|c|c|c|c|c|}
\hline متوسط & $r$, & $\operatorname{lr}$ & 11 & V7 & ا1ع & 14 & 11 & r- حرق المخلفت الزراعية علىسطح التربة \\
\hline منخفض & $|, \mu|$ & $\mathrm{VA}$ & $11 \mathrm{~V}$ & $\mid \mu, \mu$ & $r$. & $\Lambda, \mathrm{V}$ & $1 \mu$ & "ـ - لمتخدلم المخصبات الزراعية بشكل عشولئي \\
\hline 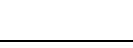 & $1, \mathrm{ro}$ & $\Lambda$. & 14. & $10, \mu$ & $\mu^{\mu}$ & $\varepsilon, 7$ & $\mathrm{~V}$ & ع - إققاء مخلفت النح \\
\hline مرقع & $r, \varepsilon \Lambda$ & $r ו, \mu$ & ז" & $9, \mu$ & $1 \varepsilon$ & $79, \varepsilon$ & $1 \cdot \varepsilon$ & 0 \\
\hline
\end{tabular}

\begin{tabular}{lllllllll}
\hline - 7 & \\
\hline
\end{tabular}

المعنوي الفريد في فعسير التباين في المتغير التايع مّ إجراء

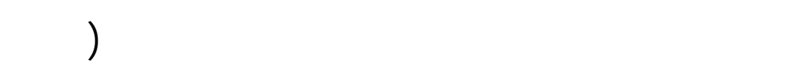

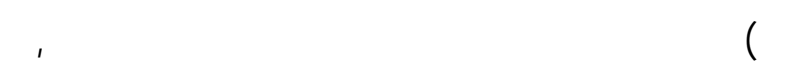

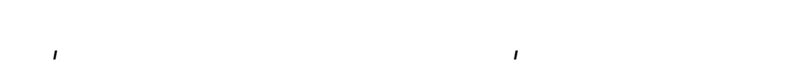

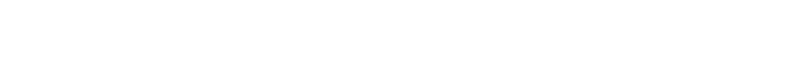

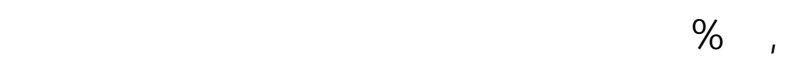

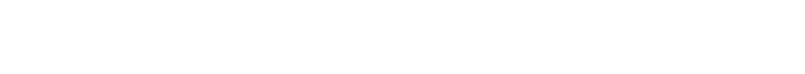
والحالة التعليمية للمبحوثة.

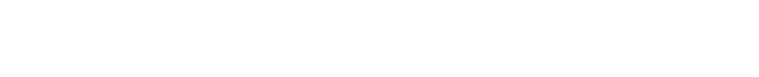

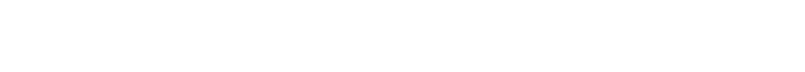

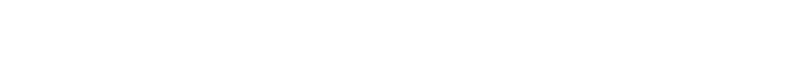

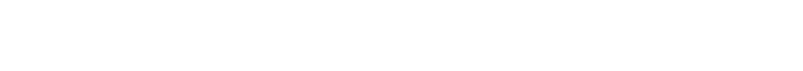
التربة، ولستخده المخصبت الزراعية بشكل عثروائي، وأن

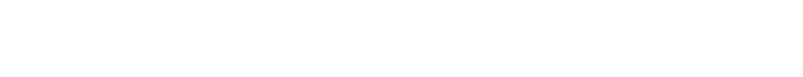

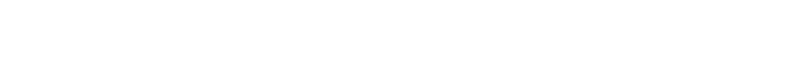

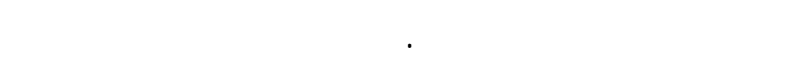

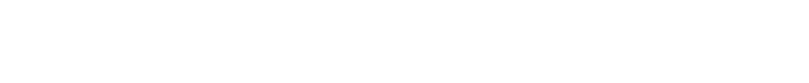

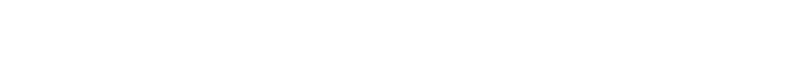
هذه الأعمل لأزولجهن لأدائها. ونظل الممارست البيئية الخطائة للريفيت المبحوثلت في لاعني

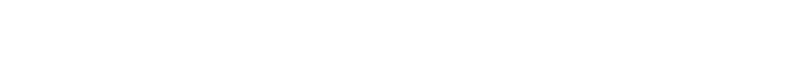

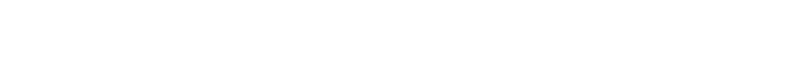
اللشهري للمأسرة ، ومستوى المعيشة.

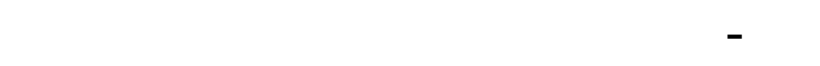
والمختل بين بهن خصائص المبحوثائ والممارسات البيئية الخلائة في بُمد الأرض الزبراعية المبحنية

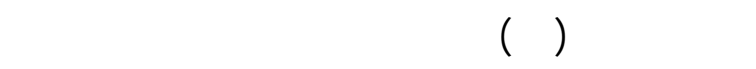

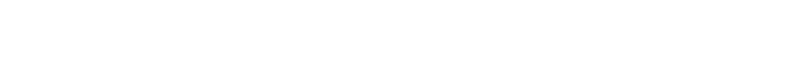

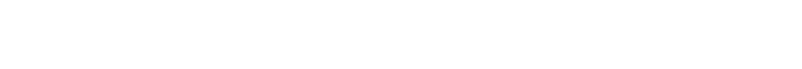

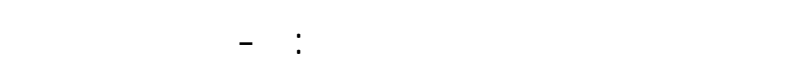

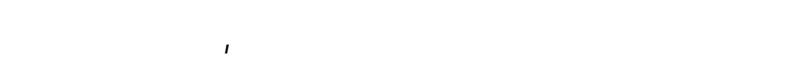

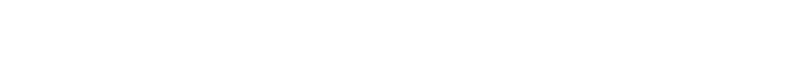

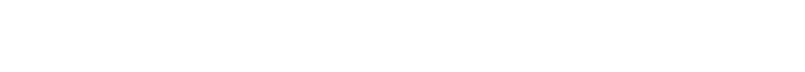

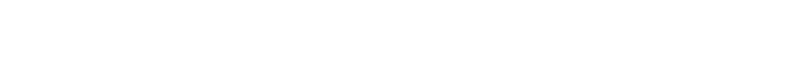

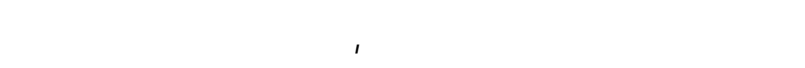

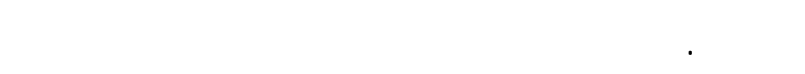

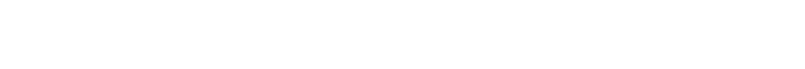

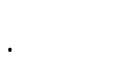

كما ويين نفس الجدول للسابق أن المتغيرات الم سنقلة

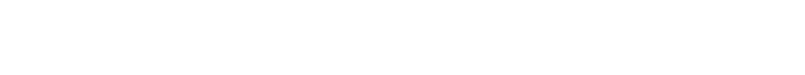

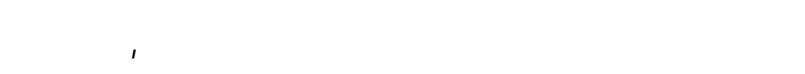

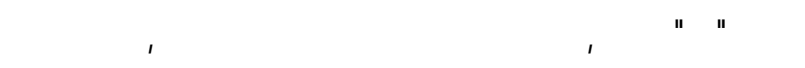
يمكن القول بوجود علاقة ارتبطية متعدة بين المتغي -رات

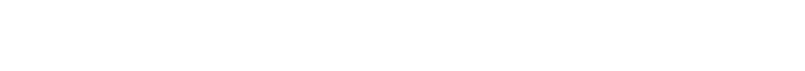

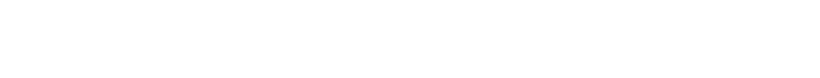

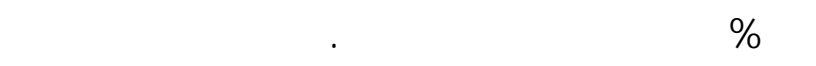




\begin{tabular}{|c|c|c|c|}
\hline معالل الانحدار الجزئي المعياري & معالمل النحدار & معالل (لارتبلا البسيطا. & المتغيرل الهسقلة \\
\hline & $\cdot, \cdot 7$ & $* *, r \backslash \Lambda-$ & عمر المبحوثة \\
\hline$* \cdot, 1 \varepsilon 7$ & $* \cdot, \mid \in \mu$ & $\cdot, \wedge r$ & الحالة التعليمية للمبحوثة \\
\hline & $\cdot, 11 Y$ & $\cdot, 10 \mathrm{r}$ & عدد أَفراد الألَسرة \\
\hline & $* \cdot, 100$ & ** . & التعرض الإعلامي \\
\hline **., $\varepsilon Y \varepsilon-$ & 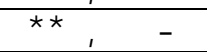 & $* * \cdot, \varepsilon \mid \cdot-$ & الافتاح الجغرافي \\
\hline$* * \cdot, r \wedge \Lambda-$ & **.,rqV- & $* * \cdot, \mu \wedge\urcorner-$ & إجمالي الدخل الشهري للمندرة \\
\hline & $\cdot, 110$ & $* ., I V Y-$ & مستوى المعيشة \\
\hline & $\cdot, \mathrm{IV7}$ & $\cdot, I \varepsilon r$ & المشاركة الآجتماعية غير الرسمية \\
\hline$\cdot$,oro & $\cdot, 0 \mathrm{VO}$ & & R معلمل الارتبط المتعدد \\
\hline$\cdot, r V 7$ & . & & R2 معلط التحنيد \\
\hline$* * \backslash \Lambda, \mu \cdot \Lambda$ & ${ }^{* *} \wedge, 07 \Lambda$ & & ق قيمة F \\
\hline
\end{tabular}

r - ضرورة قيلم الأجهزة الإعلامية كالإذاعة والتلفزي -ون والصحلة وغيرها بتخصيص وقت كالفي للبرلمج البيئية

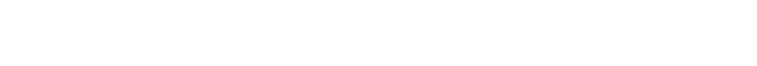
مع البيئة على أن تكون هذه البرلمج في صورة منلسبة

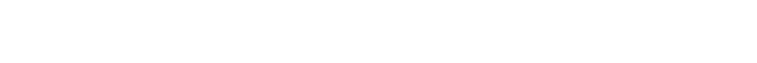
للمرأة. " - العل على لكتثلف قيادات نسائية وتنمية وعيهن البيئي

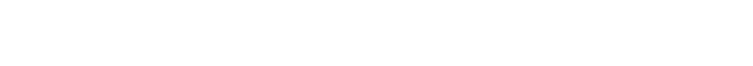
البيئي السليم بين الريفيت في المنطق الريفية المختلف ـة

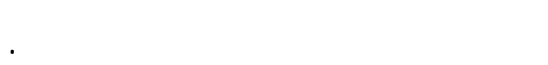
ع -لشارت نتائج النماذج المختزلة إلي إسهالم مجموعة م ن

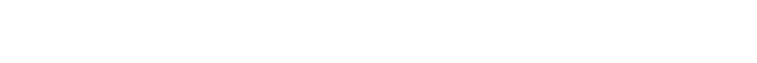
ظبيق المبحوثلت للمماسلت البيئية الخطئة لذا يج ـب

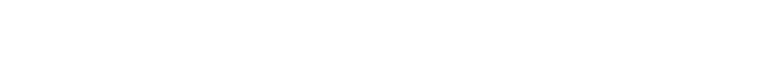
عند وضع البرامج التنموية الموجهة للمرأة الريفية. 0 - 0

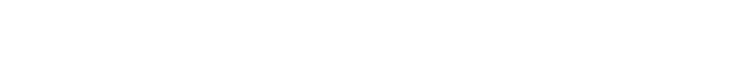

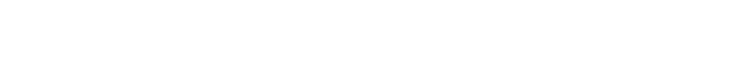

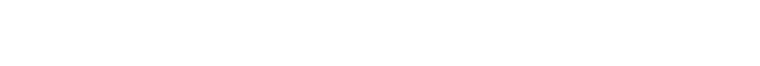

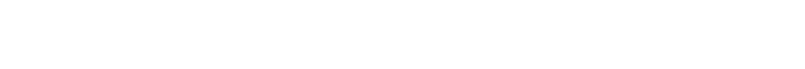

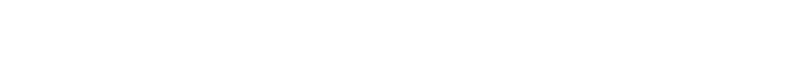

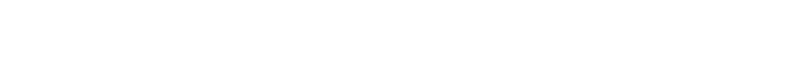
تفسير التباين في الممارست البيئية الخطئة للاريفيت ف مي هذا الُبعد.

\section{التوصيلت}

لستنادَ إلي نتائج البمث يمكن التوصية بما يلي:

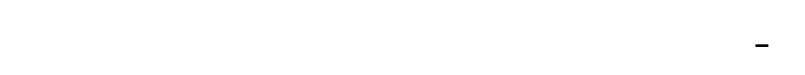
المبحوثلت للمماست البيئية الخطائة في الأبعاد الأربعة

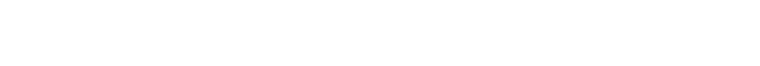

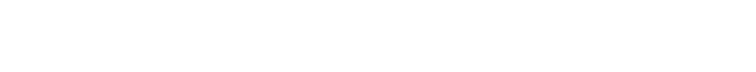

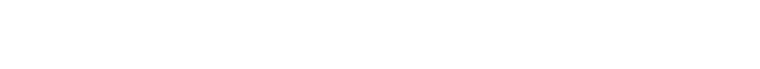
تزويد الريفيت بالمماسست البيئية الصحيحة والتي من

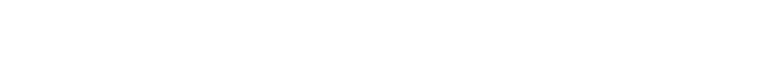
والاجتماعلت الإششادية لهن. 
عبير عبد للستار علام ولخرون.،: الممارست البيئية الخطئة للمرأة الريفية والعولمل المرتبة بها بقرية نواج...

صالح، صبري مصطفى، الإششاد الزراعي أسلسياته وظبيقاته،

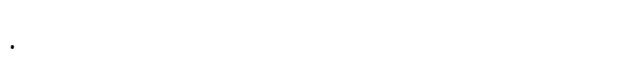

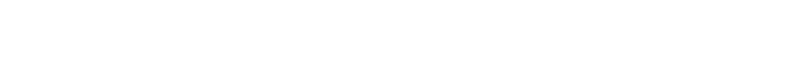

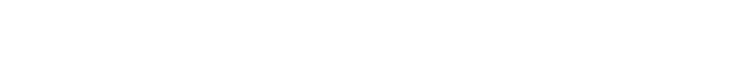

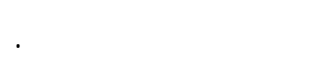

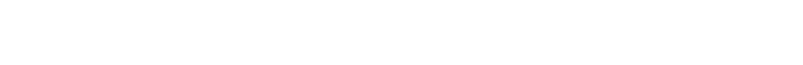

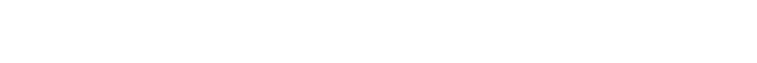

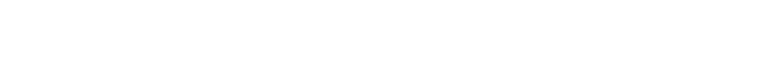

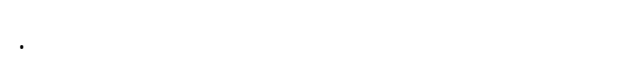

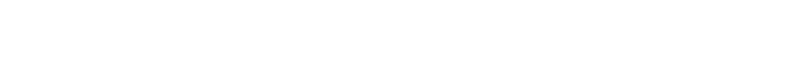

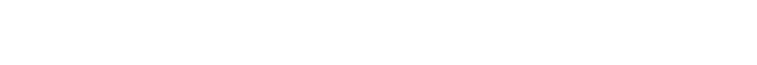

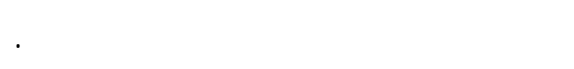

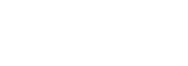

الجلاد، لحمد، البيئة المصرية وقضايا التنمي ـة، ء الم الكت ـب،

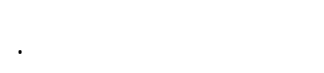

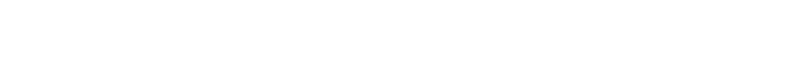
صحة الإنسان، دار المعترفة الجلمعية، الإسكندرية، 7 ـ . .م. الم.

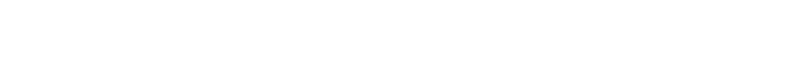
الطبوعلت الجدية، الإسكندرية، و9 ام. ام.

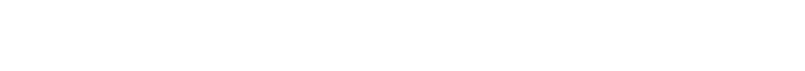

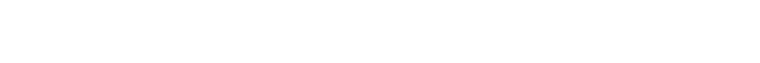

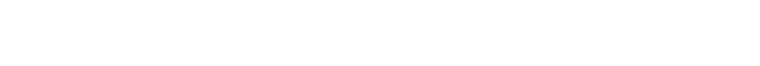

$$
\text { شهس، } 7 \text {. ."م. }
$$

عنن، نهى الزاهي اللسعيد، درلسة لمستوى معارف المرأة الريفية

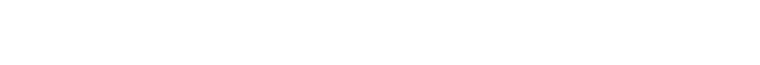

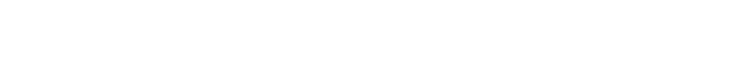
طظا، ع. . م. 


\title{
SUMMARY
}

\section{The Wrong Environmental Practices of Rural Women and Related Factors in Nawag Village, Algarbia Governorate}

\author{
Abeer Abd. El. Starr Allam, Mohamed Abd El Maksoud and Hany Mahmoud Abdel Hady Aldmhougy
}

This research aims to identify the level of rural respondents application to wrong environmental practices in four dimensions: water, air, food, and agricultural land; determine the nature of the relationship between each variable of studied independent variables and the wrong environmental practices of rural women for each dimension of the four studied dimensions; determine the relationship among combined studied independent variables and the wrong environmental practices for each one of the four dimensions studied, and finally determine the degree of contribution of each variable of studied independent variables in explaining the variation in the wrong environmental practices for each one of the four dimensions studied.

To achieve the objectives of the research; Nawag village, Algarbia governorate were to be a place of the study. A sample of 150 respondents was randomly chosen of rural women in the village. Data was collected by personal interview using a questionnaire, and frequencies, percentages, probable average, coefficient of simple correlation (Pearson), coefficient of multi correlation, the standard partial regression were used in data analysis.

The main findings of this research were as follows:

- The application level of rural to wrong environmental practices was as high as possible for air, followed by water, then by agricultural land, and finally by food where the percentage of wrong practice wrong in the medium and high level of $80 \%, 78 \%, 66.9 \%, 65.7 \%$, respectively.

- There was an inverse and significant correlation among wrong environmental practices of the respondents for water dimension and the number of family members, media effect, geographical opening, total monthly income of family, living level and unofficial social participation. As well the relationship was inversely correlated for air dimension and both of number of family members, and media effect, geographic opening, total monthly income of the family, living level and unofficial social participation. Regarding food dimension; the relationship was inverse and significant with both of media effect, geographical opening, and total monthly income of the family. Also the relationship was inverse and significant for agriculture land dimension with all of the respondents' age, media effect, geographical opening, total monthly income of the family, and the living level.

- It was clear that geographical opening variable contributed to interpretation of the variation in the four studied dimensions, while variable of total monthly income of the family contributed in explaining the variation in three dimensions: water, air, and agricultural land. In the other hand; the variable of educational status of respondent contributed to the interpretation of the variation in the two dimensions of food and agricultural land. Each variable of media effects and number of family members, and living level contributed to the interpretation of the variation in air dimension only, while the variable of media effect contributed to the interpretation of variation in food dimension only. It is also noticed that all of these variables has maintained its significant relationship with the dependent variable in each of the full and reduced model for each dimension which indicating the authenticity of these variables in explaining the variation in the dependent variable. 